\title{
Patulina: incidência e controle em derivados de maçã
}

\section{Patulin: incidence and control in apple products}

\author{
Marcos Giovani Celli ${ }^{1 *}$; Alexandre Rodrigo Coelho ${ }^{2}$; \\ Gilvan Wosiacki ${ }^{3}$; Crispin Humberto Garcia-Cruz ${ }^{4}$
}

Resumo

A patulina, 4hidroxi-4furo[3,2-c] pirano $(6 \mathrm{H})-1$, micotoxina termo-resistente, é produzida por várias espécies de fungos, comuns em vegetais, produtos derivados e principalmente em maçãs. Estudos sobre a toxicidade em animais demonstraram esta micotoxina possui caráter teratogênico, cancerígeno e imunotóxico em camundongos. Sua biossíntese é bem compreendida envolvendo uma série de reações de condensação e de oxiredução, muitas catalisadas por enzimas. O perigo da contaminação de alimentos com patulina, alerta sobre a necessidade de um controle mais rigoroso. Pesquisas recentes objetivam sua remoção e degradação, bem como aumentar a sensibilidade das análises, tornando-as mais rápidas e com menores custos. A remoção de patulina de alimentos é feita com compostos adsorventes, com inconveniente de diminuir a qualidade do produto por adsorver outros componentes desejáveis. A degradação é feita com compostos sulfurados, os quais não são permitidos em alimentos em muitos países, e pelo crescimento de leveduras, como no caso da produção de sidras. Muitas leveduras apresentam resistência contra a patulina e produzem compostos capazes de degradá-la. Aqui, foram revisadas pesquisas sobre patulina com ênfase sobre sua influência na indústria de alimentos, incidência de patulina em suco de maçã e outros alimentos, concentrações máximas permitidas, efeitos na saúde, biossíntese, remoção, degradação e métodos mais utilizados para sua detecção e quantificação.

Palavras-chave: Micotoxinas, Penicillium expansum, maçã

\begin{abstract}
The patulin, (4hydroxy-4furo[3,2-c]pyran(6H)-1), is a thermal resistent mycotoxin produced by several species of fungi are common in plants, mainly in derivatives and apples. Studies on the toxicity in animals have shown that mycotoxin has character teratogenic, and carcinogenic in mice immunotoxic. Its biosynthesis is well understood involving a series of reactions of condensation and oxiredução, many catalyzed by enzymes. The danger of contamination of food with patulin, warning about the need for a more rigorous control. Recent research aimed their removal and degradation as well as increase the sensitivity of the tests, making them faster and at less cost. The removal of patulin of food is made with composite adsorbents, with inconvenience to diminish the quality of the product by adsorbs other components desirable. The degradation is made with sulfur compounds, which are not allowed in food in many countries, and the growth of yeasts, such as the production of cider. Many yeasts have resistance against patulin and produce compounds capable degrade it. Here, we reviewed research on patulin with emphasis on its influence in food industry, incidence of patulin in apple juice and other foods, maximum permissible concentrations, health effects, biosynthesis, removal, degradation and most widely used methods for its detection and quantification.
\end{abstract}

Key words: Mycotoxin, Penicillium expansum, apple

\footnotetext{
${ }^{1}$ Farmacêutico e Bioquímico formado pela Pontifícia Universidade Católica do Paraná, Mestre em Ciência de Alimentos da Universidade Estadual de Ponta Grossa - PR, Doutorando em Engenharia e Ciência de Alimentos do Departamento de Engenharia e Tecnologia de Alimentos da Universidade Estadual Paulista - São José do Rio Preto - SP. E-mail: marcoscelli@hotmail.com.

2 Docente do Departamento de Engenharia de Alimentos da UTFPR - Francisco Beltrão - PR.

3 Docente do Departamento de Engenharia de Alimentos da UEPG - Ponta Grossa - PR.

4 Docente do Departamento de Engenharia e Tecnologia de Alimentos da UNESP-São José do Rio Preto - SP.

* Autor para correspondência
} 


\section{Introdução}

No ano de 2007 o Brasil produziu mais de 43,7 milhões de toneladas de frutas, classificando o país como o terceiro maior produtor mundial, atrás da China e da Índia, é o $15^{\circ}$ maior exportador e ocupa o $8^{\circ}$ lugar em eficiência de produção (FOOD AGRICULTURE ORGANIZATION - FAO, 2008; INSTITUTO BRASILEIRO DE FRUTAS - IBRAF, 2008). Do total produzido, $45 \%$ das frutas destinase ao consumo nacional in natura, 53\% à indústria processadora e apenas $2 \%$ à exportação de frutas frescas, evidenciando a necessidade de incentivo para agilizar maior inserção no mercado internacional (FAO, 2008). As exportações brasileiras de frutas in natura geraram divisas de 430 milhões de dólares em 2007, sendo que cerca de 65 milhões foram decorrentes da maçã e seus derivados com crescimento de $100 \%$ nas exportações da fruta in natura, passando de 53 mil toneladas em 2006 para 106 mil toneladas em 2007 (IBRAF, 2008).

Os frutos da macieira podem ser distinguidos e agrupados por suas variações de sabor, tamanho, forma, aparência, consistência da polpa e casca, e por suas distintas utilidades. De uma forma geral, as maçãs podem ser classificadas de três tipos: de mesa, para processar ou próprias à fabricação de sidra ou do vinagre. Uma mesma árvore pode fornecer frutos com diferentes aproveitamentos, de acordo com sua classificação. Pela sua capacidade de produzir fibras de boa qualidade e pelo seu alto teor de potássio, a maçã é uma fruta indicada para manutenção da saúde, prevenindo doenças cardíacas e excesso de colesterol no sangue, e para dietas de emagrecimento (TODA FRUTA, 2008).

As macieiras se desenvolvem bem em clima temperado, sendo favorável e essencial para uma boa produtividade, o que limita as regiões de plantio, mas coloca o Brasil em posição privilegiada em relação às demais nações (SIMÃO, 1998). A colheita é feita de acordo com os critérios de qualidade relacionados a características que se desenvolvem pós-colheita, durante a maturação dos frutos. Frutos destinados à comercialização imediata e à exportação são aqueles que apresentam melhor qualidade em termos de aparência, como coloração uniforme, forma característica, ausência de podridões e danos mecânicos ou machucados. Frutos com maior tamanho ou mais aromáticos, com elevado teor de sólidos solúveis e com coloração mais intensa são obtidos com colheita tardia (ARGENTA, 1993; TU; NICOLAI; BAERDEMAEKER, 2000; WATKINS et al., 1993).

Os frutos que não se destinam imediatamente ao mercado consumidor são armazenados em câmaras frigoríficas que contribuem para diminuição do seu metabolismo, conservação das características físico-químicas e diminuição no crescimento de fungos. Esta armazenagem pode ser associada à atmosfera controlada onde baixas concentrações de oxigênio e dióxido de carbono (1 e 0,5\% respectivamente) mantêm melhor a qualidade da maçã, proporcionando maior retenção da firmeza da polpa e menor incidência de degenerescência na temperatura de $-0,5^{\circ} \mathrm{C}$ (BRACKMANN; MAZARO; LUNARDI, 1998).

A extensão territorial e a diversidade climática do Brasil permitem o cultivo das mais variadas frutas, porém, o fator determinante no plantio das macieiras numa região depende do período de baixa temperatura, necessário para o repouso vegetativo e quebra de dormência (FUNDAÇÃO CARGILL, 1983). No Brasil, safra 2006/07, foram produzidas 1,1 bilhão de toneladas de maçã (INSTITUTO BRASILEIRO DE GEOGRAFIA E ESTATÍSTICA - IBGE, 2007). As exportações de maçãs in natura chegaram a 106 mil toneladas e na forma de suco de maçã a 33 mil toneladas (IBRAF, 2008). A Região Sul do país apresenta o clima mais propício para produção de maçã, sendo responsável por $98 \%$ da produção nacional na safra 2004/05, com $40 \mathrm{mil}$ toneladas $(3,6 \%)$ provenientes do Estado do Paraná (PR), 464,1 mil toneladas (42\%) do Rio Grande do Sul (RS) e 596,7 mil toneladas (54\%) de Santa Catarina (SC) (BRASIL, 2007; IBGE, 2007). As cultivares predominantes de maçã são Gala e Fuji, com 
representatividade de 46 e $45 \%$, respectivamente, em relação à produção total (ASSOCIAÇÃO BRASILEIRA DOS PRODUTORES DE MAÇÃ ABPM, 2008).

No ano de 2000, o Brasil exportou mais de 60 mil toneladas de maçã para a Europa e está atingindo autosuficiência na suplementação do mercado interno, recebendo destaque entre os frutos exportados, devido à vantagem na diferença de periodicidade em relação ao Hemisfério Norte (IBRAF, 2005). A safra nacional de maçã 06/07 atingiu 1113,8 mil toneladas, indicando aumento de $31,2 \%$ em comparação com os dados da produção anterior (produção de 849 mil toneladas) (IBGE, 2007).

O suco de maçã é o produto extraído da fruta por moagem ou prensagem (pressão), passando por um processamento de clarificação, adição de antioxidante, desaeração, pasteurização e envase, sem adição de açúcar, adoçante ou conservantes. $\mathrm{O}$ produto final se apresenta como líquido límpido, claro e brilhante (KOZLOWSKA et al., 2003; WOSIACKI et al., 2002). O suco também pode receber adição de polpa para melhorar sua consistência ou adição de açúcar para corrigir a doçura, sendo então chamado de néctar de maçã.

Como acontece com a maioria das produções agrícolas, existe uma fração de safra de maçã que acaba não sendo comercializada no mercado in natura, que pode chegar a $30 \%$ da produção nacional, sendo destinado à industrialização (WOSIACKI; NOGUEIRA; SILVA, 2000). A indústria consumiu $18,9 \%$ da produção nacional de maçãs na safra $01 / 02$, $81,1 \%$ destinado ao comércio da fruta in natura, sendo 7,6\% destes para exportação (ABPM, 2008). Com o aumento da produção nacional, aumentaram as exportações da fruta in natura e a venda para as fábricas de suco (WOSIACKI et al., 2002). A maior parte da produção nacional de suco concentrado de maçã destina-se à exportação, apresentando grande concorrência com a Argentina e Chile, países com tradição no processamento de maçãs e grandes produtores mundiais (PRADO, 2000).
No Brasil, o comércio interno de suco de fruta é em torno de 5 a 7 litros anuais por habitante, decorrente do alto preço, falta de divulgação, incentivo, investimentos e de disponibilidade de variedades. Essa produção e comercialização de suco é insignificante quando comparado com a Europa e os Estados Unidos, onde o consumo de sucos de fruta chega a 30 litros anuais por habitante, destacando-se o suco de maçã como o mais popular e segundo suco mais consumido no mundo (GALCIACLOSAS et al., 2004; IBRAF, 2008; WOSIACKI; DEMIATE; CHERUBIM, 1995).

O Ministério da Agricultura define o suco de maçã como sendo a bebida não fermentada e não diluída, obtida da parte comestível da maçã (Malus domestica Borkh) por processo tecnológico adequado devendo obedecer aos Padrões de Identidade e Qualidade, fixados para suco de fruta (BRASIL, 2000).

Pelo regulamento técnico para fixação dos padrões de identidade e qualidade para suco de maçã, deverá obedecer as características e composição. A cor deve ser translúcida, o aroma próprio, sólidos solúveis num mínimo de $10,5^{\circ} \mathrm{Brix}\left(20^{\circ} \mathrm{C}\right)$, acidez total acima de $0,15 \mathrm{~g} / 100 \mathrm{~g}$ expressa em ácido málico, acidez volátil no máximo de $0,04 \mathrm{~g} / 100 \mathrm{~g}$ expressa em ácido acético e açúcares totais naturais do fruto até 13,5g/100g (BRASIL, 2000).

Países da Europa e EUA também estabelecem níveis máximos para conteúdo de patulina em derivados de maçã. A Organização Mundial da Saúde (OMS) recomenda concentrações inferiores à $50 \mu \mathrm{g} / \mathrm{L}$ e o Food and Drug Administration (FDA) publicou um documento, "The Draf Guidance Document of FDA Components and Industry on Apple Juice and Apple Juice Products", que estabelece o limite de 50 $\mu \mathrm{g} / \mathrm{L}$ para sucos de maçã e derivados (RICHARD et al., 2003). A União Européia adotou recentemente este mesmo nível máximo e também $25 \mu \mathrm{g} / \mathrm{kg}$ em produtos sólidos incluindo compota de maçã e purê de maça e ainda o nível máximo permitido de 10 $\mu \mathrm{g} / \mathrm{kg}$ é proposto para produtos de maçã destinados a crianças (FONSECA, 2008). 
Uma das principais preocupações em relação à contaminação do suco de maçã com a patulina é o fato de que o Brasil exporta este produto a países que possuem limites estabelecidos por legislação para esta micotoxina em sucos (MELLO, 2004).
Na Tabela 1 observa-se que os países que tem legislação seguem a recomendação da OMS e da FDA de no máximo $50 \mu \mathrm{g} / \mathrm{L}$ de patulina em suco de maçã.

Tabela 1. Países que possuem legislação para patulina e o limite máximo permitido.

\begin{tabular}{ccc}
\hline País & Tipo de alimento & Limite $(\mu \mathrm{g} / \mathrm{L}$ ou $\mu \mathrm{g} / \mathrm{kg})$ \\
\hline Alemanha & Suco de maçã & 50 \\
Áustria & Suco de frutas & 50 \\
Finlândia & Todos os alimentos & 50 \\
França & Suco de maçã e produtos derivados & 50 \\
Grécia & Suco de maçã e produtos de maçã & 50 \\
Israel & Suco de maçã & 50 \\
Itália & Suco de frutas & 50 \\
Noruega & Suco de maçã concentrado & 50 \\
& Todos os alimentos & 50 \\
República Tcheca & Alimentos para crianças & 30 \\
& Alimentos infantis & 20 \\
& & 50 \\
Romênia & Todos os alimentos & 30 \\
Suécia & Rações & 50 \\
Suíça & hSuco de frutas & 50 \\
Uruguai & Suco de frutas & 50 \\
\hline
\end{tabular}

Fonte: Fonseca (2008).

\section{Patulina}

A patulina, 4hidroxi-4furo[3,2-c]pirano $(6 \mathrm{H})-1$ (Figura 01), uma micotoxina termo-resistente da classe hidroxifuropiranona e também chamada clavicina, claviformina ou expansina, apresenta fórmula empírica $\mathrm{C}_{7} \mathrm{H}_{6} \mathrm{O}_{4}$ e seu peso molecular é de 154,12 Da. Pode ser produzida como metabólito secundário por várias espécies de fungos para inibir o crescimento de outros microrganismos. A patulina foi isolada pela primeira vez de Penicillium claviforme, nomeada claviformina, mas em razão de seu freqüente isolamento partindo de Penicillium patulum, chama-se patulina. Inicialmente era considerada um antibiótico, mas pelos seus efeitos tóxicos em animais, foi classificada como uma toxina. Apresenta estabilidade em ácidos diluídos e é resistente à temperatura de $125^{\circ} \mathrm{C}$ na faixa de $\mathrm{pH}$ entre 3,5 e 5,5, ocorrendo o inverso em soluções alcalinas e compostos sulfurosos representados por metabissulfito e radicais sulfidrilas, quando diminui a sua atividade biológica (ENGEL; TEUBER, 1984; GONÇALEZ; PINTO; FELICIO, 2001; SCUSSEL, 1998). Sua atividade carcinogênica é atribuída à insaturação $\alpha, \beta$, junto com uma dupla ligação conjugada externa, unida na posição 4 do anel lactona. Apresenta absorção UV máxima de 256,5 nm e solubilidade em água e solventes orgânicos comuns, exceto éter de petróleo (MAJERUS; KAPP, 2002; MOAKE; PADILLA-ZAKOUR; WOROBO, 2005; RYCHLIK; SCHIEBERLE, 2001). 


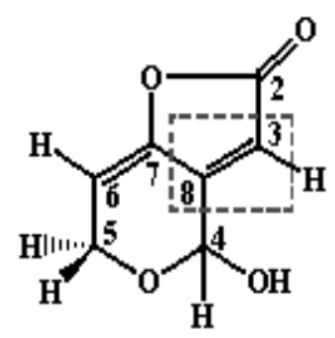

Figura 1. Estrutura molecular da Patulina Fonte: MOSS, 2008.

Formada pela via das policetidas (Figura 02), a patulina causa efeitos tóxicos em animais, de caráter teratogênico e cancerígeno em camundongos, além de lesões pulmonares, hepáticas e renais (GÖKMEN; ACAR, 1998a; RICHARD et al., 2003), efeitos gastrointestinais e neurotóxicos (HOPKINS, 1993) e imunotóxicos (SHARMA, 1993). A dose de letalidade $-\mathrm{DL}_{50}$ para camundongos varia de 5 a $30 \mathrm{mg} / \mathrm{kg}$ de peso corpóreo (BOONZAAIJER; BODELDIJK; VAN OSENBRUGGEN, 2005). Segundo pesquisadores, a dupla ligação presente na estrutura da patulina interage com os ácidos nucléicos, afetando a transcrição gênica e a síntese de biomoléculas (ARAFAT; MUSA, 1995; HATEZ; GAYE, 1978; MIURA; HASUMI; HENDO, 1993; MOULE; HATEY, 1977), também ocasiona o rompimento da membrana do protoplasma (MAHFOUD et al., 2002; RILEY; SHOWKER, 1991) e inibição da produção de interferon (WICHMANN; HERBARTH; LEHMANN, 2002). O resultado destes estudos é, como um todo, inconclusivo em humanos, mas sugere que sintomas agudos pelo consumo de patulina podem incluir agitação, convulsões, congestão pulmonar, edema, ulceração, hiperemia, distensão gastro-intestinal, hemorragia intestinal, degeneração de células epiteliais, inflamação intestinal, vômitos e danos nos rins (MAHFOUD et al., 2002; MCKINLEY; CARLTON; BOON, 1982). Após ingestão, a patulina é rapidamente excretada (cerca de $87 \%$ ), sendo $49 \%$ nas fezes, $36 \%$ na urina e 1 a $2 \%$ pela via respiratória na forma de dióxido de carbono (MOSS, 2008).

A produção de patulina ocorre quando a taxa de crescimento diminui em virtude das limitações do consumo de nitrogênio (GROOTWASSINK; GAUCHER, 1980). A biossíntese de patulina está definida e envolve uma série de reações de condensação e de oxiredução, muitas, se não todas, catalisadas por enzimas. Sua síntese é iniciada com uma unidade de acetil-Coenzima A e três unidades de malonil-Coenzima A, sendo condensados em ácido 6-metilsalicilico (6-MAS) pela ação da enzima ácido 6-metilsalicilico sintetase (6-MAS sintetase). A próxima etapa envolve a conversão de 6-MAS em m-cresol pela atividade da 6-MAS descarboxilase. M-cresol é convertido em álcool $\mathrm{m}$-hidroxibenzil através da $\mathrm{m}$-cresol hidrolase. $\mathrm{O}$ próximo passo é conversão doálcoolm-hidroxibenzil a gentisaldeido pela enzima álcool m-hidroxibenzil desidrogenase, tendo como intermediário de reação o m-hidroxibenzaldehido ou o álcool gentisil. Uma vez formado o gentisaldeido, é convertido para isopoxidona, filostina, neopatilina, E-ascladiol e para patulina (GRIFFIN, 1993). 


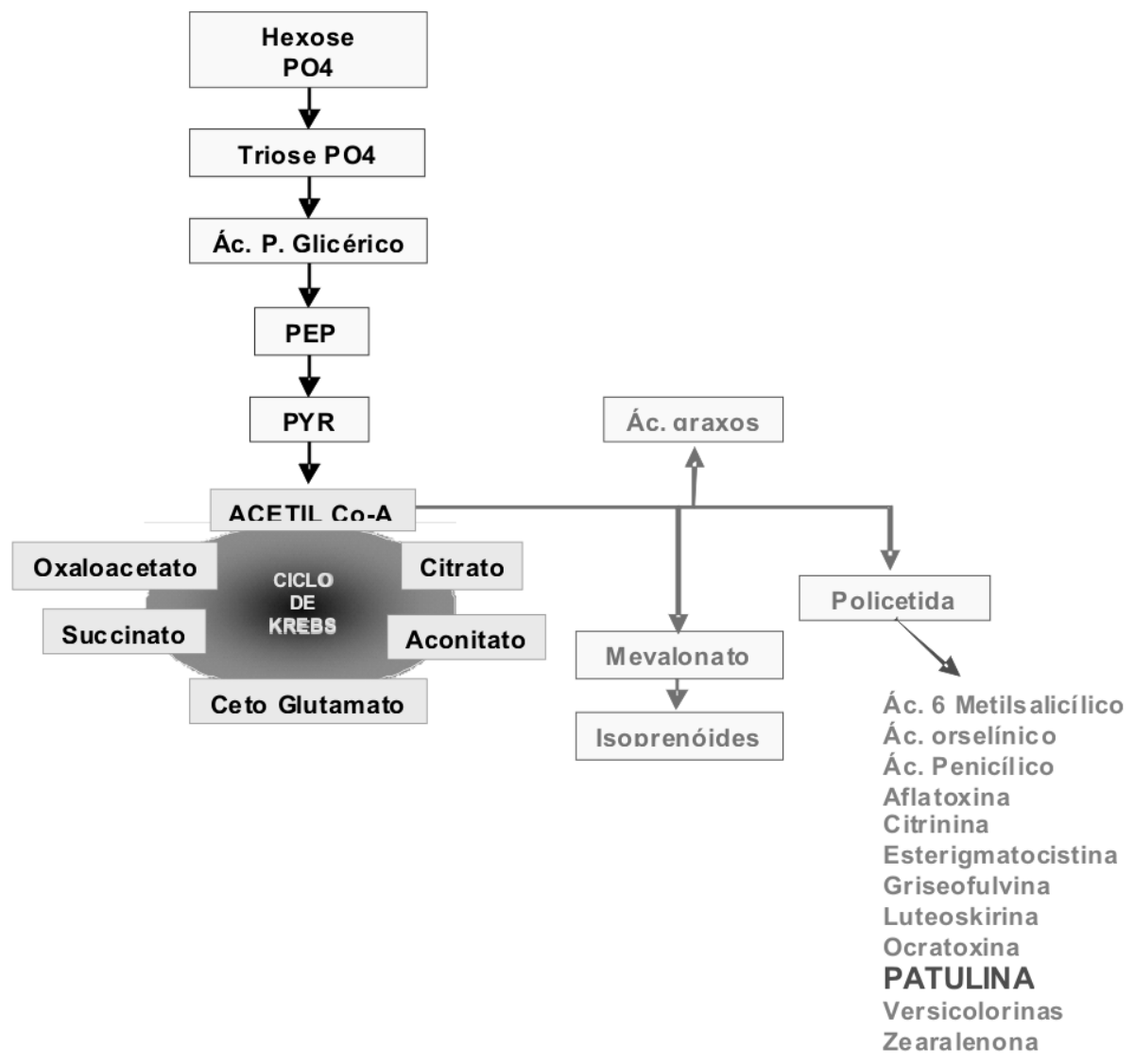

Figura 2. Via de formação da patulina.

Fonte: GRIFFIN (1993).

Selmanoglu e Kockaya (2004) investigaram os efeitos tempo-dependentes de patulina nos níveis de triiodotironina (T3), tetraiodotironina (T4), hormônio tireóide estimulante (TSH), testosterona, hormônio luteinizante (LH) e hormônio de crescimento $(\mathrm{GH})$ no desenvolvimento de ratos masculinos de 5-6 semanas de idade por um período de 60 e 90 dias. A dose de patulina utilizada foi baseada em níveis de exposição humana $(0,1 \mathrm{mg} /$ $\mathrm{kg}$ de peso corporal/dia). Ao término da experiência foram verificados os níveis de hormônio no soro e análise histopatológica por microscopia da tireóide e testículos. Os resultados revelaram que, após 60 dias de ingestão, os ratos apresentaram um aumento de $66,6 \%$ nos níveis de testosterona e uma diminuição de 17,3\% nos níveis de T4. Quando passados os 90 dias de ingestão de patulina, os níveis de testosterona estavam aumentados em $75 \%$ e LH em $146 \%$. Os exames histopatológicos do testículo demonstraram hiperplasia local no tecido intersticial e também desorganização do epitélio do tubo seminífero. A tireóide revelou infiltração de células linfóides e aumento do tecido intersticial entre os folículos e degeneração coloidal.

Iwahashi et al.(2006) caracterizaram a citotoxicidade da patulina em leveduras por análise de transcrição observando a resposta nas leveduras após exposição a 50ppm de patulina. Encontraram a expressão de genes patulina-induzidos, semelhantes à expressão de genes obtidos após tratamento com substâncias agrícolas antifúngicas $\left(\right.$ maneb $^{\circledR}$ e zineb $\left.^{\circledR}\right)$. Além disso, o tratamento com patulina ativou a degradação de proteínas, especialmente as atividades de proteossoma, metabolismo de aminoácidos sulfurados e sistema de defesa contra oxidação. Sugeriram danos no DNA por alquilação, o qual era 
reparado por recombinação e outros mecanismos de reparos. Os resultados também proveram genes biomarcados para a descoberta de patulina em produtos agrícolas. Os resultados sugeriram a possibilidade de aplicar o sistema de transcrição das leveduras para avaliação de substâncias químicas, especialmente para substâncias naturais que são difíceis de resistir à síntese orgânica.

Embora não exista nenhum dado toxicológico ou epidemiológico em seres humanos, a patulina vem sendo empregada como indicador de qualidade nos frutos e produtos de maçã (MOSS, 1996). O Ministério Britânico de Agricultura, Pesca e Alimentos (MAFF) tem monitorado os níveis de patulina em sucos de maçã desde 1980. Quando contaminações acima de $50 \mu \mathrm{g} / \mathrm{L}$ foram confirmadas pela primeira vez, em 1992, foi sugerido o limite máximo permitido de até $50 \mu \mathrm{g} / \mathrm{L}$, que foi confirmado em 1995 (UNITED KINGDOM, 1993). Com o estabelecimento de programas de controle, a redução dos níveis de patulina em sucos de maçã alcançou 60\% (UNITED KINGDOM, 1998). Outros países como Suécia, Bélgica e Noruega também estabeleceram concentração máxima permitida de até $50 \mu \mathrm{g} / \mathrm{L}$, como recomendado pela Organização Mundial de Saúde (OUGH; CORISON, 1980).

Em 2001, o Food and Drug Administration (FDA) publicou um documento, "The Draf Guidance Document of FDA Components and Industry on Apple Juice and Apple Juice Products", que estabelece o limite de $50 \mu \mathrm{g} / \mathrm{L}$ para sucos de maçã e derivados (RICHARD et al., 2003), embora a União Européia tenha estabelecido $25 \mu \mathrm{g} / \mathrm{kg}$ em compotas e purês e $10 \mu \mathrm{g} / \mathrm{kg}$ em produtos infantis (BOONZAAIJER; BODELDIJK; VAN OSENBRUGGEN, 2005; COMMISSION OF THE EUROPEAN COMMUNITIES, 2003). A Organização Mundial de Saúde (OMS) alterou o limite de ingestão de 7,0 para $0,4 \mu \mathrm{g} / \mathrm{kg}$ de peso corpóreo/dia (BAERT et al., 2004; BOLGER, 2002).

A patulina é produzida por mais de 60 espécies de fungos e cerca de 30 gêneros (LAI;
FUH; SHIH, 2000). Dentre esses Penicillium expansum (P. leucopus), P. patulum (P. urticae, $P$. griseofulvum), $P$. crustosum, $P$. roqueforti, $P$. claviforme, Paecilomyces spp., Saccharomyces vesicarium, Alternaria alternata, Byssochlamys nivea, B. fulva, Aspergillus giganteus, A. terreus, e A. clavatus (AYTAC; ACAR, 1994; LAIDOU; THANASSOULOPOULOS; LIAKOPOULOUKYRIAKIDES, 2001; MOSS; LONG, 2002), destacando-se com especial importância e interesse o Penicillium expansum, parasita facultativo que invade frutas danificadas causando podridão, mais comum em maçãs, podendo assim ocorrer patulina em suco de maçã fresco. Normalmente encontrada em altas concentrações na parte da fruta onde há presença de esporos (93 a 95\% de toda toxina), difundindo-se para outras partes sadias do fruto devido sua hidrossolubilidade, até $4 \mathrm{~cm}$ além da lesão (BAERT et al., 2004; LAIDOU; THANASSOULOPOULOS; LIAKOPOULOUKYRIAKIDES, 2001). Também produzida por Aspergilus clavatus em materiais como resíduos de cevada malteada e restos de cereal no campo. Byssochlamys nívea e Byssochlamys fulva também produzem patulina e são importantes em silagem (SCUSSEL, 1998). Microrganismos produtores de patulina também já foram isolados de uvas, cerejas, pêras, damascos, nectarinas, pêssegos, tomates, mirtilo e amêndoas (DEMIRCI; ARICI; GUMUS, 2003; JIMINEZ et al., 1991; LEGGOTT; SHEPHARD, 2001; PRIETA et al., 1994; RITIENI, 2003).

Penicillium spp é o fungo toxigênico de maior incidência em maçãs, considerado um parasita de ferimentos, cresce em atividade de água $\left(\mathrm{a}_{\mathrm{w}}\right)$ entre 0,83 a 0,99 e tem a capacidade de tolerar até $80 \%$ de sacarose (p/v) no meio de crescimento, causando podridão de coloração azul na parte externa da maçã e bege ou marrom-clara no tecido, deixando o fruto aguado e mole (HEFNAWY; ABOU-ZEID, 2003). Stott e Bullerman (1975), verificaram as espécies de fungos que contaminavam naturalmente maçãs, encontrando que $66 \%$ tem a capacidade de 
produzir patulina, sendo eles do gênero Penicillium, Aspergillus e Byssoclamys.

Dombrink-Kurtzman e Blackburn (2005) avaliaram diferentes espécies de Penicilium sp. para determinar sua toxicidade em diferentes meios de cultivo. Para isto, utilizaram 11 espécies toxigênicas dos fungos, P. expansum (4), P. griseofulvum (3), P. clavigerum (2), P. coprobium (1) e Penicillium sp. (1) isolado de maçã. As culturas foram crescidas em meios líquidos Batata Dextrose, Extrato de Malte e Extrato de Levedura peptonado adicionado de glucose, ambos com e sem suplementação de manganês, totalizando seis formulações diferentes. A quantificação foi realizada por Cromatografia Líquida de Alta Eficiência com detector UV. Os três $P$. griseofulvum apresentaram maior produção de patulina ao final do experimento. Para a maioria das cepas, o Caldo Batata Dextrose complementado com manganês propiciou máxima produção da micotoxina. Embora P. expansum seja citado como provável fonte de patulina em sucos de maçã, outras espécies de Penicillium podem ser mais toxigênicas, devendo a indústria estar alerta à possibilidade destas outras serem as responsáveis pela ocorrência de patulina.

Hasan (2000) determinou as espécies de fungos predominantes e ocorrência de micotoxinas em maçãs sadias (100) e deterioradas (100). Também avaliou o efeito do tempo e temperatura sobre o crescimento de $P$. expansum em meio contendo glucose, $\mathrm{NaNO}_{3}, \mathrm{KH}_{2} \mathrm{PO}_{4}, \mathrm{MgSO}_{4}, \mathrm{KCl}$ e extrato de maçã e a inibição da produção de patulina e aflatoxina utilizando óleos de frutas. Aspergillus flavus (100\%), Aspergillus niger (63\%), Penicillium expansum (50\%) e Rhizopus stolonifer (50\%) eram os fungos isolados com maior freqüência em frutas saudáveis. A. niger era o microrganismo mais comum em maçãs deterioradas (83\%), seguido por A. flavus (67\%), P. expansum (58\%), R. stolonifer (53\%) e Alternaria alternata (42\%). As micotoxinas encontradas em maçã podre foram patulina e aflatoxina. A temperatura ótima para produção de patulina por $P$. expansum foi de $15^{\circ} \mathrm{C}$ após 15 dias. Utilizando $0,2 \%$ de óleo de limão no meio de cultivo, foi inibida completamente a produção de patulina e com $0,05 \%$ de óleo de limão mais $0,2 \%$ de óleo de laranja reduziu mais de $90 \%$ da produção. A formação de aflatoxina foi reduzida em $90 \%$ quando era utilizado $0,2 \%$ de óleo de limão. A freqüente ocorrência de P.expansum produtor de patulina em frutas aponta a importância do controle durante o armazenamento das maçãs para evitar riscos de ingestão de toxina, devendo ser removido o tecido danificado antes da utilização do fruto.

Baseado nos tratamentos de lavagem de maçãs antes do armazenamento em câmaras frias, Chen, Ingham e Ingham (2004), avaliaram a efetividade desses tratamentos em maçãs cultivar Empire com relação ao crescimento de $P$. expansum NRRL 2304 e produção de patulina. Para os tratamentos foram utilizados satinitizantes empregados na indústria (solução de 200 ppm NaOCl, 1\% StorOx ${ }^{\circledR}, 0.5 \%$ sorbato de potássio, $300 \mathrm{ppm} \mathrm{SO}_{2}$, e $0 \%$ a $5 \%$ de solução de ácido acético). Esporos de $P$. expansum foram inoculados em fatias de maçãs e, então, mergulhadas nas soluções por $5 \mathrm{~min}$. $\mathrm{O}$ crescimento do fungo e a produção de patulina foram monitorados durante o armazenamento subseqüente. Encontraram que a solução de sorbato de potássio $(0,5 \%)$ e a de $\mathrm{SO}_{2}(300 \mathrm{ppm})$ não afetou a sobrevivência do fungo ou produção de patulina. StorOx ${ }^{\circledR}(1 \%)$ foi efetivo contra os esporos em solução (destruição de $4 \log$ de Número Mais Provável de esporos), mas não teve efeito quando os esporos estavam inoculados em fatias de maçãs. A lavagem com 200 ppm de $\mathrm{NaOCl}$ dificultou o crescimento de $P$. expansum em discos de maçã inoculados, mas não inibiu completamente a produção de patulina. A solução ácido acética (2 a $5 \%$ ) foi a substância química mais eficiente contra P. expansum. Um tratamento de lavagem com $2 \%$ de ácido acético por $1 \mathrm{~min}$ foi suficiente para inibir por completo o crescimento do fungo e subseqüente produção de patulina em maçãs armazenadas destinadas à produção de suco e sidra.

A produção de diferentes metabólitos de $P$. expansum isolados de culturas de origem pura foi 
demonstrada por Andersen, Smedsgaard e Frisvad (2004). Ao contaminar frutas e produtos de frutas, o fungo produz substâncias tóxicas diferentes da patulina. Enfocaram a atenção das legislações e das indústrias alimentícias no problema relacionado aos metabólitos de P. expansum. De acordo com a literatura, este fungo pode produzir citrinina, ocratoxina A, patulina, penitrem A, e rubratoxina $\mathrm{B}$. Neste estudo a produção qualitativa de metabólitos foi examinada usando Cromatografia em Camada Delgada (260 fungos), Cromatografia Líquida de Alta Eficiência (85 fungos), e Espectrometria de Massas (22 fungos). Os resultados mostraram que nenhum dos 260 fungos isolados produziu ocratoxina A, penitrem A ou rubratoxina B. Porém, quetoglobosina $\mathrm{A}$ e comunesina $\mathrm{B}$ foram produzidos constantemente por todos os fungos. Patulina e roquefortina $\mathrm{C}$ foram produzidos por $98 \%$ dos fungos isolados e descobertos expansolidas $\mathrm{A} / \mathrm{B}$ e citrinina em 91 e $85 \%$, respectivamente.

Abrunhosa et al. (2001) determinaram o potencial micotoxigênico de fungos isolados de uvas destinadas à produção de vinho de duas regiões vinho-produtoras de Portugal. Os fungos toxigênicos isolados (51) foram identificados como Penicillium expansum produtores de patulina e/ou citrinina, as quais foram quantificadas por Cromatografia em Camada Delgada, e nenhum fungo produtor de ocratoxina foi encontrado. Quando os fungos eram crescidos em Extrato de Levedura acrescido de sacarose, favorecia a produção de citrinina (51 cepas) e desfavorecia a produção de patulina (20 cepas). Quando cultivaram os fungos em suco de uva, 33 cepas produziram patulina enquanto citrinina foi produzida por apenas uma das cepas. A presença de micotoxinas em vinhos de uva é discutida. A contaminação das uvas com patulina pareceu não contribuir para contaminação do vinho. As uvas da cultivar Douro apresentavam contaminação por $P$. expansum, mas as uvas da cultivar Vinho Verde não apresentavam tal contaminação. Isto se deu pela resistência dos cultivares à fungos ou por sofrer influência de fatores ambientais.
Tratamentos pós-colheita com fungicidas são utilizados para reduzir as deteriorações do fruto, como por exemplo, a aplicação do fungicida sintético imazalil (Freshgard ${ }^{\circledR}$ e Fungaflor $^{\circledR}$ ) em maçãs (NUNES et al., 2001), mas cepas de $P$. expansum acabam desenvolvendo resistência (CONWAY et al., 2004; JANISIEWICZ et al., 2003). Em vista do interesse na ampliação da exportação de frutas brasileiras, o controle na armazenagem se tornou essencial para garantir a qualidade (IBRAF, 2008). Os consumidores cada vez mais conscientes vem impondo exigências quanto à necessidade de produtos isentos de resíduos de agrotóxicos (CONWAY et al., 2004; WISNIEWSKI; WILSON, 1992).

Métodos alternativos são desenvolvidos para o controle do bolor azul como a utilização de microrganismos antagônicos (COELHO et al., 2007; LEVY et al., 2000) aplicação de antibióticos naturais (BATTA, 2004; SHOLBERG; BEDFORD; STOKES, 2005), aplicação de produtos sanitizantes (CONWAY et al., 2004).

Okull e Laborde (2004) deixaram esporos de Penicillium expansum expostos à oxidação eletrolítica (19,0 A) para verificar essa influência sobre a viabilidade desses esporos. O teste foi realizado em uma suspensão aquosa contendo o fungo ( $10^{6}$ esporos $\left./ \mathrm{mL}\right)$ e em maçãs inoculadas com os esporos ( $10^{6}$ esporos) imersas em solução de cloridrato de sódio $(0,1 \%)$. Aplicada a força eletrolítica máxima e de $50 \%$, diminuiu a população de esporos viáveis por 4 e 2 unidades logarítmicas, respectivamente. A oxidação eletrolítica não preveniu a formação posterior da lesão na fruta inoculada diretamente com $P$. expansum, porém, ocorreu a formação de uma lesão menor quando as maçãs foram armazenadas. Concluíram que a oxidação eletrolítica é uma potencial alternativa como desinfetante, podendo substituir o cloro no controle de infecções de maçãs por $P$. expansum durante o armazenamento e processamento das frutas. 
Inicialmente as pesquisas para controle biológico eram direcionadas aos metabólitos bacterianos que demonstravam perspectivas promissoras para restringir o uso de agrotóxicos químicos (SANHUEZA; KRETZCHMAR; BORSÓI, 1992). Florianowicz (2001) mostrou a eficiência da atividade antifúngica de Bacillus megaterium, Bacillus subtillis, Lactobacillus casei, L. delbrueckii e L. lactis contra P. expansum. Nunes et al. (2001) relataram excelente controle exercido por Pantoea agglomerans (CPA-2) contra B. cinerea $\mathrm{e}$ P. expansum sob refrigeração, evidenciada pela redução de mais de $80 \%$ na deterioração de pêra $\left(8,0 \times 10^{7} \mathrm{UFC} / \mathrm{mL}\right)$ causada por $P$. expansum e Rhyzopus stolonifer $\left(10^{3}\right.$, $10^{4}$ e $10^{5}$ conídias $/ \mathrm{mL}$ ). Usall et al. (2001) obtiveram resultados satisfatórios utilizando Candida sake (cepa CPA-1) no biocontrole de doenças pós-colheita causadas por $P$. expansum em maçãs, reduzindo a incidência de frutas deterioradas em mais de $70 \%$. O tratamento de maçãs (cultivar Golden Delicious) pós-colheita com $C$. sake sob estocagem a frio em duas estações (1994/5 e 1995/6) também resultou no controle efetivo de $P$. expansum, com redução de $80 \%$ no diâmetro da lesão e $50 \%$ na ocorrência das lesões (TEIXIDO; USALL; VINAS, 1999). No Brasil, Tavares (1996) obteve uma redução de $P$. expansum em até $80 \%$, utilizando Bacillus subtillis e $B$. thuringiensis, sendo o resultado obtido superior ao controle químico.

As leveduras e seus metabólitos também vêm sendo estudados para utilização no controle biológico. Levy et al. (2000) analisaram o potencial antagônico de 18 leveduras contra Penicillium spp produtor de patulina, avaliando o potencial e a estabilidade dos compostos ativos produzidos, utilizando o sobrenadante do meio de leveduras para realização de antibiograma. Testes indicaram que o sobrenadante de uma levedura \#38 (Saccharomyces cerevisiae comercial) apresentou maior halo e tempo de inibição. Esta atividade mostrou perspectivas para aplicação, porém, após 7 dias o efeito antagônico diminuiu devido à baixa estabilidade do composto responsável pela inibição, restringindo a aplicabilidade. Sob a forma de microrganismos vivos, os autores abrem perspectivas para estender ensaios com armazenagem a médio e longo prazo.

Em estudo realizado por Coelho (2005), do total de 44 leveduras isoladas (16 de frutas, 10 de silagem de milho e 18 de formigueiro de laboratório), 5 apresentaram antagonismo perante esporos de Penicillium expansum toxigênico (107 $\mu \mathrm{g}$ patulina/mL) em Ágar Meio para Levedura, associado à antibiose (produção de substância extracelular), sendo Pichia ohmeri 158 e Candida guilliermondii $\mathrm{P} 3$ as de maior atividade antagônica. No antifungigrama em meio líquido (caldo MPL) o sobrenadante do cultivo de Candida guilliermondii $\left(25^{\circ} \mathrm{C} / 72\right.$ horas) inibiu $58,2 \%$ da germinação dos esporos de Penicillium expansum, e Pichia ohmeri $\left(25^{\circ} \mathrm{C} / 48\right.$ horas) inibiu o desenvolvimento de hifas em $66,17 \%$, sugerindo mecanismo associado ao caráter killer, uma vez que ambas as leveduras foram positivas perante as linhagens padrão Saccharomyces cerevisiae NCYC 1006 e Pichia kluyveri CAY-15.

Pesquisas mostraram que nem todos os produtos de maçã estão livres de patulina (SHILIHA; ASKAR, 1999). Alimentos infantis como os purês de maçãs, freqüentemente utilizados em papinhas de bebê, podem apresentar elevada contaminação, o que se torna mais preocupante pelo efeito correlato de dose ingerida $\mathrm{x}$ peso corporal. Os produtos comerciais obtidos a partir de maçã com maior valor agregado são os sucos clarificados e/ou reconstituídos e os fermentados, base para sidras (BISSESSUR; PERMAUL; ODHAV, 2001).

A presença de patulina em sucos de maçã está relacionada à contaminação da matéria-prima com fungos produtores da micotoxina e é de conhecimento técnico que o processo de clarificação não diminui significativamente o conteúdo de patulina no suco, mas em pequena quantidade (16\%) (BISSESSUR; PERMAUL; ODHAV, 2001). A temperatura empregada para pasteurização ou para produção de suco concentrado $\left(80^{\circ} \mathrm{C}\right)$ 
acaba por degradar patulina, mas apenas num percentual pouco significativo (20\%). A utilização de radiação diminui as concentrações da toxina no suco de maçã causando pequenas alterações na coloração e nas concentrações de ácido ascórbico (ZEGOTA; ZEGOTA; BACHMAN, 1988). Pesquisas mostraram que os sucos clarificados e reconstituídos brasileiros não apresentaram teores de patulina preocupantes (SYLOS; RODRIGUESAMAYA, 1999), contendo níveis abaixo do máximo recomendado pela Organização Mundial da Saúde (OMS) de $50 \mu \mathrm{g} / \mathrm{L}$, supostamente pela utilização de matéria-prima de boa qualidade.

Em 1999, pesquisadores de São Paulo-Brasil determinaram a incidência de patulina em frutas e sucos de frutas comercializados em Campinas utilizando-se de técnicas de Cromatografia Líquida de Alta Eficiência com detector UV e estabelecendo o limite de detecção de $5 \mu \mathrm{g} / \mathrm{L}$ com Cromatografia em Camada Delgada para confirmação (SYLOS; RODRIGUES-AMAYA, 1999). Dentre as 30 amostras testadas, compostas de sucos comerciais adquiridos no mercado nacional, apenas em uma foi detectada a presença de patulina com a concentração de $17 \mu \mathrm{g} / \mathrm{L}$. Os autores realizaram testes de recuperação mediante metodologias de diversos pesquisadores tendo obtido resultados diferentes porém aceitáveis dada a pequena variabilidade encontrada, e levantam a hipótese que a baixa incidência de patulina possa estar relacionada à sulfitagem dos sucos comerciais, permitido pela legislação brasileira, mas nada foi feito para confirmação. Utilizando a mesma metodologia para detecção da toxina, Prado et al. (2000) verificaram a incidência de patulina em 13 amostras de suco de maçã comercializadas em Belo Horizonte, Minas Gerais-Brasil, e encontraram níveis detectáveis (10 $\mu \mathrm{g} / \mathrm{L})$ de patulina em apenas uma das amostras.

$\mathrm{Na}$ Itália, Beretta et al. (2000) analisaram 82 amostras de produtos da maçã produzidos no país, concluindo que todas as amostras apresentaram boa qualidade, estando com concentrações de patulina inferiores a $50 \mu \mathrm{g} / \mathrm{L}$. Ritieni (2003) analisou três procedimentos de extração de patulina utilizados para suco de maçã, sucos clarificados, alimento infantil e vinagre de maçã comercializados na Itália. Relatou que o método descrito por MacDonald et al. (2000), o qual remove proteínas com sulfato de amônio sem adição de enzima, como sendo aquele que apresentou melhor recuperação, além de ser rápido e de baixo custo. A solução clareada deste método também pode ser analisada por Cromatografia Líquida de Alta Eficiência sem problemas. Dentre as amostras analisadas, somente uma delas apresentou nível superior ao permitido $(50 \mu \mathrm{g} / \mathrm{L})$; esta amostra era o purê de maçã orgânico com agente anti-microbiano (metabissulfito de sódio) com uma concentração de $74,2 \mu \mathrm{g} / \mathrm{L}$.

Lai, Fuh e Shih (2000) estudaram as condições de Cromatografia Líquida de Alta Eficiência de fase reversa em coluna de $\mathrm{C}_{18}$ com detecção UV a $276 \mathrm{~nm}$ e avaliaram seu desempenho utilizando Cromatografia Gasosa para confirmação, visto que a Espectrometria de Massas foi ineficiente para confirmar baixas concentrações. Ao utilizar um volume de injeção de $50 \mu \mathrm{L}$, o limite de detecção calculado em suco de maçã foi de aproximadamente $0,05 \mu \mathrm{g} / \mathrm{L}$ e o limite de quantificação de $15 \mu \mathrm{g} / \mathrm{L}$, abaixo de $20 \mu \mathrm{g} / \mathrm{L}$ como sugerido pela Association of Official Analytical Chemists - AOAC (2000). As taxas de recuperação atingidas foram satisfatórias, variando de 93,1 a 96,6\%. As análises mostraram que das 105 amostras de sucos, 83,1\% estavam livres de patulina e $11,4 \%$ apresentaram pequenas quantidades, encontrando-se, ainda, dentro dos limites aceitáveis de no máximo $50 \mu \mathrm{g} / \mathrm{L}$ recomendado pela OMS.

Harwig et al. (1973) constataram alta ocorrência de $P$. expansum aliada à presença de patulina em $46 \%$ das maçãs naturalmente deterioradas, sob armazenagem sem refrigeração no Canadá, indicando aceleração na produção da toxina devido à conservação inadequada. $\mathrm{O}$ mesmo ocorreu com suco de maçã na Austrália, onde $65 \%$ das amostras apresentaram-se contaminadas por patulina (WATKINS; FAZERAS; PALMER, 1990). 
United Kingdom (1999) e Brackett e Marth (1979) detectaram acima de $50 \mu \mathrm{g} / \mathrm{L}$ e 10 a $350 \mu \mathrm{g} / \mathrm{L}$ de patulina em 2,5 e $58 \%$ de amostras de sucos de maçã em Londres (Inglaterra) e Wisconsin (EUA), respectivamente. De 100 amostras de suco de maçã analisadas para verificação da incidência de patulina na Espanha, 82 estavam contaminadas, sendo que sete apresentaram níveis acima de $50 \mu \mathrm{g} / \mathrm{L}$ (PRIETA et al., 1994). A incidência de patulina também foi observada por Burda (1992) em 23\% das 328 amostras de suco analisadas entre 1989/1990 no Reino Unido, com níveis da toxina entre 51 e 1130 $\mu \mathrm{g} / \mathrm{L}$ em 73 amostras.

A contaminação com patulina em 215 amostras de suco concentrado de maçã foi detectada na Turquia, com valores variando de 7 a $376 \mu \mathrm{g} / \mathrm{L}$ (GÖKMEN; ACAR, 1998b). Lindroth e Niskanen (1978) relataram a ocorrência de patulina em $20 \%$ dos sucos de maçã industrializados e $40 \%$ nos sucos caseiros, constatando-se no último grupo concentrações maiores que $1000 \mu \mathrm{g} / \mathrm{L}$, provavelmente devido a condições inadequadas de estocagem, aliada à matéria-prima de baixa qualidade. Steiner, Werner e Washutti (1999) demonstraram a presença de níveis altos de patulina $(500-2500 \mu \mathrm{g} / \mathrm{L})$ em sucos de maçã, quando processados com frutas deterioradas. Boonzaaijer, Bobeldijk e Van Osenbruggen (2005) avaliaram a presença de patulina em 63 produtos comerciais derivados de maçã comercializados na Holanda e não encontraram níveis quantificáveis da toxina na maioria das amostras, porém a amostra de suco orgânico de maçã apresentou a toxina. Em uma pesquisa realizada em 42 amostras comerciais de suco e 23 de suco concentrado de maçã no Irã em 2002, a patulina foi detectada em 33 e 56\%, respectivamente, com níveis superiores a $50 \mu \mathrm{g} / \mathrm{L}$, cujo valor máximo foi $285,3 \mu \mathrm{g} / \mathrm{L}$ (CHERAGHALI et al., 2005).

Em estudo realizado por Jackson et al. (2003), avaliou-se como as condições de armazenamento afetam os níveis de patulina. A patulina não foi detectada em maçãs selecionadas, colhidas diretamente das árvores e não pasteurizadas, mas foi detectada, em altos níveis, em maçãs que tiveram contato com o solo no momento da colheita, durante seu armazenamento ou processamento e que também não foram pasteurizadas. $\mathrm{O}$ mesmo foi observado no concentrado desses dois tipos de maçãs armazenado por 4 a 6 semanas em temperatura de 0 a $2^{\circ} \mathrm{C}$.

Outra pesquisa foi desenvolvida a fim de avaliar a produção de patulina em maçãs nos cultivares Gala e Fuji inoculados com $P$. expansum (NRRL 1172) e $P$. variabile isolado de maçãs. Para isso, foram utilizadas temperaturas de armazenamento empregadas na industria $\left(0^{\circ} \mathrm{C}\right)$, de câmara fria $\left(4^{\circ} \mathrm{C}\right)$ e temperatura ambiente $\left(25^{\circ} \mathrm{C}\right)$ nos tempos de 15,30 , 60 e 90 dias. A produção de patulina ocorreu em todas as combinações de armazenagem, constatando que à medida que se elevava a temperatura, era acelerado o desenvolvimento dos fungos e a produção de patulina. A $0^{\circ} \mathrm{C}$ o aparecimento de patulina só foi detectado em 60 dias, a $4^{\circ} \mathrm{C}$ em 30 dias e a $25^{\circ} \mathrm{C}$ em 15 dias. As variações de $\mathrm{pH}$ não foram significativas e a deterioração macroscópica aumentava conforme o aparecimento de toxina. Os autores concluíram que os riscos freqüentes de produção de patulina nas temperaturas de refrigeração indicam a necessidade de melhor controle nos estágios de colheita e armazenagem de maçãs (ROSS et al., 1998).

Marín et al. (2006) avaliaram o grau de contaminação por patulina em maçãs infectadas com $P$. expansum, armazenadas à temperatura ambiente $\left(20^{\circ} \mathrm{C}\right)$ por curtos períodos de tempo (5 dias) e sua relação com a cultivar (Golden ou Fuji), grau de maturação, tamanho das lesões e capacidade migratória da toxina no tecido sadio. Altas concentrações de patulina foram encontradas em maçãs Golden, maduras e que apresentavam lesões maiores. A migração da toxina pelo tecido sadio da fruta era maior quanto maior o tamanho da lesão, chegando a $4 \mathrm{~cm}$ quando apresentavam grandes áreas afetadas e de $2 \mathrm{~cm}$ em lesões menores. Entre 2 a $6 \%$ de patulina migrou para o tecido sadio, estando mais concentrada no diâmetro de $1,5 \mathrm{~cm}$ da lesão. Os autores sugerem que a remoção do tecido afetado e tecido sadio próximo é uma boa prática para prevenção de toxina em derivados de maçã. 
Morales et al. (2007), avaliaram a produção de toxina por Penicillium expansum toxigênico isolado de frutos em maçãs maduras cultivar Golden, com e sem aplicação de fungicida (Folpet ${ }^{\circledR}$, tiabendazol e imazalil), durante armazenamento a $1^{\circ} \mathrm{C}$ por 6 semanas. Em nenhum fruto foi detectada a presença de toxina, indicando que a temperatura de armazenamento inibiu a produção de toxina pelo microrganismo. Em adição, mantiveram esses frutos à temperatura de $20^{\circ} \mathrm{C}$ por 3 dias, simulando a temperatura e tempo de transporte. Neste caso, observaram o aparecimento de lesões significativas com semelhante acúmulo de patulina em todos os frutos, indicando que o tratamento com fungicida não alterou a produção de toxina pelo fungo.

Wilson e Nuovo (1973) isolaram 60 cepas de $P$. expansum produtoras de patulina em maçãs com deterioração, mantidas sob armazenagem de $0^{\circ} \mathrm{C}$. Northolt, Van Egmonde Paulsch (1978) confirmaram o fato, constatando o desenvolvimento e produção de patulina em maçãs armazenadas à $1^{\circ} \mathrm{C}$. Rychlik e Schieberle (2001) avaliaram a capacidade migratória da toxina em maçãs, encontrando concentrações de patulina em porções de até $4 \mathrm{~cm}$ de distância da lesão, sendo essas com valor menor que $6 \times 10^{-5} \mu \mathrm{g}$ de patulina/g de tecido sadio. Celli (2006) quantificou a concentração de patulina em podridões de maçã, bem como o tecido sadio ao redor da lesão $(1 \mathrm{~cm})$. Encontrou patulina em todos os tecidos deteriorados

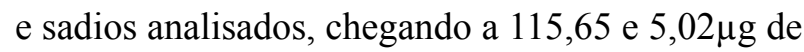
patulina/g de tecido, respectivamente.

Martins et al. (2002), verificaram a ocorrência simultânea de patulina e citrinina, micotoxinas produzidas principalmente por fungos Penicillium sp. e Aspergilus sp., respectivamente, em 351 podridões de maçã de diferentes cultivares, utilizando Cromatografia em Camada Delgada para detecção e quantificação. O nível de detecção foi de 120-130 $\mu \mathrm{g} / \mathrm{kg}$ para patulina e de $15-20 \mu \mathrm{g} / \mathrm{kg}$ para citrinina. Do total de amostras, $68,6 \%$ estavam contaminadas somente com patulina, 3,9\% somente com citrinina e $19,6 \%$ contaminadas com patulina e citrinina, simultaneamente. A concentração de patulina chegou à $80,50 \mathrm{mg} / \mathrm{kg}$ na cultivar Richared, e a de citrinina $0,92 \mathrm{mg} / \mathrm{kg}$ na cultivar Rome Beuaty, não sendo encontradas concentrações elevadas de ambas em uma mesma amostra. Os autores concluíram que maçãs que apresentam porções deterioradas apresentam risco ao ser humano se consumidas, como fruta ou suco de fruta, uma vez que podem conter elevada concentração de patulina.

Uma verificação da possível contaminação por patulina no aroma de maçã, um destilado de interesse comercial produzido durante a concentração de suco, foi realizada por Kryger (2001). O autor produziu um aroma de maçã a partir de um suco com elevada taxa de toxina (3420 ppb) e verificou que nenhuma patulina foi encontrada no destilado. Destacou, por outro lado, que ocorreu diminuição desta micotoxina presente no suco concentrado, mas que essa diminuição era decorrente do tratamento térmico empregado, o que já tinha sido relatado por outros pesquisadores. As concentrações de toxina reduziram aproximadamente 33\% num tratamento térmico a $100^{\circ} \mathrm{C}$ por 3 horas sob vácuo. Das análises realizadas em 4 amostras de aromas comerciais, nenhuma apresentou níveis detectáveis de patulina.

Como a patulina é um parâmetro de qualidade em sucos de maçã, Kadakal, Nas e Ekinci (2004) determinaram a presença de ergosterol e patulina em sucos contaminados para verificar se havia alguma relação entre elas. Foram analisados sucos produzidos a partir de maçãs sadias, e a partir de maçãs deterioradas apresentando 30\%, 60\% e $100 \%$ da área contendo podridão. Utilizando Cromatografia Líquida de Alta Eficiência com detector diodo array para quantificação de patulina e de ergosterol, encontraram concentrações crescentes de ambos à medida em que aumentavam as podridões da matéria prima, variando de 1,9 à $861,0 \mu \mathrm{g}$ de patulina/L $(\mathrm{R}=0,99)$ e de 0,7 à 111,0 $\mathrm{mg}$ de ergosterol/L $(\mathrm{R}=0,99)$. Ao correlacionar todas as concentrações de patulina e ergosterol, encontraram um coeficiente de correlação linear de 0,98 . Concluíram que, assim como a patulina, o ergosterol também pode ser utilizado como um controle microbiológico em maçãs. 
Gökmen e Acar (1998a) investigaram a relação entre a patulina e o ácido fumárico em 70 sucos comerciais de maçã concentrados para determinar se a presença de ácido fumárico é decorrente da atividade microbiológica da matéria-prima. Tanto a patulina, micotoxina produzida em maçãs principalmente por Penicillium expansum, como o ácido fumárico, formado a partir do ácido málico sintético adicionado no suco de maçã durante a concentração do suco ou pelo crescimento de Rhizopus spp, foram quantificados porCromatografia Líquida de Alta Eficiência. Nenhuma correlação significante foi encontrada para as amostras com níveis de patulina abaixo que $50 \mu \mathrm{g} / \mathrm{L}$. As amostras que continham níveis de 67 a $216 \mu \mathrm{g}$ de patulina/L tiveram um coeficiente de correlação ligeiramente mais alto de 0,55 . O coeficiente de correlação mais significante $(0,71)$ foi determinado quando todas as 70 amostras eram correlacionadas. Este estudo indicou que a presença de ácido fumárico em suco de maçã é devido a atividade microbiológica da matéria-prima, porém, o tratamento de calor aplicado para concentração do suco, também propicia grande aumento desses níveis.

Pesquisas apontam que maçãs orgânicas apresentam maiores níveis de patulina que maçãs convencionais, sendo que essa maior contaminação se deve ao não tratamento com fungicidas, o que provavelmente resultou em maior incidência de fungos toxigênicos e, conseqüentemente, de patulina nessas frutas (MALMAURET et al., 2002; PIEMONTESE; SOLFRIZZO; VISCONTI, 2005). A Tabela 2 mostra a ocorrência de patulina em sucos de maçã e derivados comercializados em alguns países.

Bebidas fermentadas não devem apresentar teores detectáveis de patulina, uma vez que as leveduras fermentativas degradam a toxina em condições anaeróbias. Em meio contendo patulina a levedura é induzida a produzir composto(s) capaz(es) de degradar a toxina. (LIPOWSKA et al., 1990; STINSON et al., 1978). Sumbu, Thonart e Bechet (1983) mostraram que a degradação de patulina por leveduras está associada a um mecanismo de defesa do microrganismo e depende da síntese de proteínas, uma vez que esta micotoxina não era degradada quando adicionada simultaneamente com cicloheximida, um inibidor de síntese protéica.

Drilleau e Bohoun (1973) analisaram 8 sidras francesas e 5 sidras dos EUA, encontrando patulina em 5 e 4 amostras, respectivamente. Visto os processos utilizados, a contaminação apresentada nestas sidras provém do uso de matéria-prima com elevado grau de contaminação ou por alguma modificação nas etapas de produção como longo período entre a obtenção do suco e o início da fermentação, onde o crescimento fúngico e a produção de toxina continuam.

Em 2003 a Agência Britânica de Segurança Alimentar (FOOD STANDARDS AGENCY FSA, 2003) realizou um estudo em 100 amostras de sidras comerciais, não encontrando concentrações detectáveis de patulina (limite de detecção de 3 $\mu \mathrm{g} / \mathrm{L})$. Enfatiza que o processo fermentativo por S. cerevisiae é capaz de degradar de 93 a $99 \%$ da toxina inicial.

$\mathrm{Na}$ indústria, o uso de conservantes durante o processamento de frutas se tornou uma necessidade para garantir a saúde dos consumidores por sua capacidade de preservar a qualidade dos produtos derivados (LEITÃO, 1990). A ação do metabissulfito é um fato comprovado, com vantagem na capacidade de degradar a patulina (ROSS, 1995). Além da degradação de patulina por compostos sulfurados, os estudos promissores mencionam outras alternativas com eventual utilidade, citando-se a remoção das partes deterioradas do fruto antes do processamento, porém pouco viável para as indústrias (CHERAGHALI et al., 2005; SYDENHAM et al., 1995), adsorção da toxina pelo uso de carvão ativado (KADAKAL; NAS, 2002; LEGGOTT et al., 2001), e desintoxicação biológica efetuada pela microbiota presente no próprio fruto (HARWIG et al., 1973; KARLOVSKY, 1999; ROSS, 1995; WALKER; MCLEOD; HODGSON, 1995). 
Tabela 2. Ocorrência de patulina em sucos de maçã e derivados em alguns países.

\begin{tabular}{ccccc}
\hline País & $\begin{array}{c}\mathrm{n}^{\circ} \text { de amostras } \\
\text { analisadas }\end{array}$ & $\begin{array}{c}\mathrm{n}^{\circ} \text { amostras } \\
\text { positivas }\end{array}$ & $\begin{array}{c}\text { Concentração de } \\
\text { patulina }(\mu \mathrm{g} / \mathrm{L})\end{array}$ & Referência \\
\hline Brasil & 30 & $1(3,5 \%)$ & $<17$ & $\begin{array}{c}\text { Sylos e Rodrigues-Amaya (1999) } \\
\text { Trucksess e Tang (1999) }\end{array}$ \\
EUA & 10 & $2(20 \%)$ & $80-110$ & United Kingdom (1999) \\
Inglaterra & 40 & $1(2,5 \%)$ & $>50$ & Prado et al. (2000) \\
Brasil & 13 & $1(7,5 \%)$ & $<10$ & Beretta et al. (2000) \\
Itália & 82 & $2(2,5 \%)$ & $0,68-1150$ & Gökmen e Acar (2000) \\
Turquia & 482 & $162(33,5 \%)$ & $50-376$ & Leggott e Shephard (2001) \\
África do Sul & 20 & $6(30 \%)$ & $5-45$ & Fernández-Trevejo, Arias Verdés, \\
Cuba & 20 & $1(5 \%)$ & $<1,72$ & Sersa Espinosa (2001b) \\
Suécia & 39 & $5(13 \%)$ & $2-50$ & Fernández-Trevejo, Arias Verdés, \\
Turquia & 45 & $27(60 \%)$ & $19,1-732,8$ & Sersa Espinosa (2001b) \\
Bélgica & 43 & $35(81,5 \%)$ & $0,7-17,3$ & Yurdun, Omurtag e Ersoy (2001) \\
Itália & 21 & $5(24 \%)$ & $5,8-56,4$ & Tangni et al. (2003) \\
Japão & 76 & $15(20 \%)$ & $1,4-45,6$ & Ritieni (2003) \\
Itália & 67 & $28(42 \%)$ & $0,07-69,3$ & Ito et al. (2004) \\
Irã & 23 & $18(78 \%)$ & $15-149$ & Piemontese, Solfrizzo e Visconti \\
Holanda & 63 & $1(1,5 \%)$ & $<25$ & Cheraghali et al. (2005) \\
Brasil & 27 & $3(11 \%)$ & $3-7$ & Boonzaaijer, Bodeldijk, Van \\
& & & Osenbruggen (2005) \\
Iha e Sabino (2008)
\end{tabular}

Koca e Eksi (2005) investigaram o efeito da temperatura de armazenamento sobre a redução de patulina em sucos concentrados durante 6 meses, mantidos a $22^{\circ} \mathrm{C}$ e a $30^{\circ} \mathrm{C}$, contaminados com toxina nas concentrações de 64,105 e $150 \mu \mathrm{g} / \mathrm{L}$. Os resultados demonstraram uma redução de patulina tempo e temperatura dependentes. Após 1 mês de armazenamento a $22^{\circ} \mathrm{C}$ a redução foi de 45 a $64 \%$ e a $30^{\circ} \mathrm{C}$, de $66-86 \%$, sendo gradativo até o quarto mês, quando não encontraram teores detectáveis da toxina.

Gökmen et al. (2001) analisaram os efeitos da clarificação sobre a concentração de patulina, compostos fenólicos e ácidos orgânicos no suco de maçã. Os processos de clarificação empregados utilizaram tratamento enzimático para floculação seguidos de combinações de gelatina e bentonite, carvão ativado, ultrafiltração, resina adsorvente e/ ou polivinilpolipirrolidona (PVPP). A clarificação convencional que utiliza gelatina, bentonita e carvão ativado demonstrou ser a mais eficaz na redução de patulina $(40,9 \%)$, porém, esta técnica causou uma diminuição significante na intensidade da cor e de compostos fenólicos no suco, afetando diretamente os padrões de identidade. A clarificação empregando ultrafiltração seguida de tratamento com resina adsorvente também resultaram na diminuição notável de patulina $(11,0 \%)$, trazendo melhorias na cor e transparência do suco. O PVPP não apresentou nenhum efeito sobre os teores de patulina, mas removeu drasticamente a concentração de fenóis. A composição de ácidos orgânicos não foi afetada pelas técnicas empregadas.

O carvão ativado, por suas propriedades adsorventes, foi usado para reduzir os níveis de patulina em suco de maçã, porém, sabe-se que a 
aparência e o sabor do suco podem ser afetados pelo tratamento (HUEBNER et al., 2000; KADAKAL; NAS, 2002; LEGGOTT et al., 2001).

A cinética de adsorção da patulina em carvão ativado, energia de ativação e calor de adsorção foi avaliado por Mutlu, Hizarcioglu e Gökmen (1997). Os pesquisadores estabeleceram uma aproximação para investigar o mecanismo de adsorção em carvão ativado de um grupo de substâncias químicas importantes nos sucos de fruta, selecionando a patulina como a substância química modelo. A cinética de sua adsorção em carvão ativado era determinada por curvas isotérmicas de adsorção de equilíbrio a qual variou de 20 à $80^{\circ} \mathrm{C}$ e concentrações de patulina de 100 à 400 ppb. Constantes da taxa de adsorção aparentes $\left(\mathrm{K}_{\text {aapp }}\right)$ foram alterados de $1,07 \times 10^{-3}$ para $1,86 \times 10^{-3} /$ g.min enquanto a temperatura aumentava. Para as curvas de adsorção de equilíbrio, foi empregado o modelo de Langmuir e parâmetros ajustados $\left(\mathrm{K}\right.$ e $\left.\mathrm{Q}^{\circ}\right)$ foram obtidos para diferentes temperaturas. Energia de ativação e calor de adsorção era determinada em sistema de adsorção do grupo $(\mathrm{Ea}=2,02 \mathrm{kcal} / \mathrm{mol}$ e $\Delta \mathrm{H}=$ $2,24 \mathrm{kcal} / \mathrm{mol}$ ). Concluíram que a adsorção ocorreu endotermicamente através de mecanismos físicos, a dependência de temperatura na cinética de adsorção foi descrita pelo modelo de Langmuir na fórmula de Arrhenius e o calor estável da patulina no processo em grupo foi reduzido ao mínimo.

Um material constituído de partículas de carvão ativado ligado a grãos de quartzo foi desenvolvido e caracterizado por Huebner et al. (2000) para remover a patulina em solução aquosa. Para confirmar a eficiência do material desenvolvido utilizaram um micro invertebrado aquático (Hydra attenuata) que possui baixa tolerância a toxinas. Sua sensibilidade a torna ideal para avaliar a toxicidade de diversos compostos químicos, como a patulina. Os resultados indicaram que o material estudado reduz em até $76 \%$ o nível de patulina em suco de maçã naturalmente contaminado.

Três tipos diferentes de carvão ativado (NORIT SA 4, NORIT SX 4 e NORIT CA 1) tiveram seu potencial avaliado na redução de patulina em suco concentrado de maçã, provendo uma desintoxicação de sucos com níveis elevados da toxina. Os tratamentos foram realizados em sucos com $12^{\circ} \mathrm{Brix}$ e $120 \mathrm{ng}$ de patulina/mL e outro com $20^{\circ}$ Brix e $160 \mathrm{ng}$ de patulina/mL, utilizando diferentes dosagens de carvão e temperaturas para verificar sua influência. O carvão NORIT SA 4 e o NORIT SX 4 exibiram curvas isotérmicas de adsorção semelhantes numa dosagem de $1 \mathrm{~g} / \mathrm{L}$. Eles alcançaram reduções de $80 \%$ e $70 \%$ de patulina, respectivamente, em $12^{\circ}$ Brix e à $55^{\circ} \mathrm{C}$. A semelhança em desempenho entre eles (carvão-vapor ativado) indicou que a pureza e a acidez de superfície não influenciam a adsorção de patulina. O carvão quimicamente-ativado (NORIT CA 1) era menos efetivo na remoção de patulina, reduzindo $45 \%$ da concentração inicial numa dose de $1 \mathrm{~g} / \mathrm{L}$. A remoção da patulina foi influenciada pelo Brix do suco, sendo que em Brix mais elevados a dose de carvão ativado requerido para remoção equivalente era maior. Numa dose de $1 \mathrm{~g} / \mathrm{L}$, NORIT SA 4 removeu $45 \%$ da patulina em suco com $20^{\circ}$ Brix, enquanto a mesma dose removeu $80 \%$ da patulina em suco com $12^{\circ}$ Brix. A remoção de patulina dos sucos por NORIT SA 4 (dose $1 \mathrm{~g} / \mathrm{L}$ ) não foi influenciada pelas mudanças de temperatura entre 30 a $65^{\circ} \mathrm{C}$. Em conclusão, o carvão ativado NORIT SA 4 provou ser o tratamento mais efetivo para a redução das concentrações de patulina em suco de maçã utilizando menores dosagens (LEGGOTT et al., 2001).

O efeito da quantidade e do tempo de contato do carvão ativado sobre a concentração de patulina em suco de maçã foi estudado por Kadakal e Nas (2002). O melhor resultado foi obtido quando utilizaram 3 gramas de carvão ativado por litro de suco com tempo de contato de 5 minutos, obtendo redução na concentração de micotoxina de 62,2 para $30,8 \mu \mathrm{g} / \mathrm{kg}$.

Karlovsky (1999) citou a desintoxicação de patulina por leveduras durante os processos fermentativos. Harwig et al. (1973) eliminaram a patulina submetendo o suco de maçãà fermentação de 
duas semanas por Saccharomyces spp. As leveduras destinadas à fabricação de sidras, constituídas de $S$. cerevisiae industriais, removeram eficientemente a patulina (BURROUGHS, 1977).

Stinson, Osman e Bills analisaram em 1979, a solubilidade dos produtos da degradação da patulina ocasionado pelo processo fermentativo utilizando para isto, toxina marcada com ${ }^{14} \mathrm{C}$. Encontraram pelo menos 6 diferentes produtos que migraram durante a Cromatografia em Camada Delgada além de um componente majoritário, imóvel. Relataram também a formação de pequena quantidade de $\mathrm{CO}_{2}$ a partir da patulina.

Diferente de Stinson, Osman e Bills (1979) que haviam relatado a formação de $\mathrm{CO}_{2}$, Moss e Long (2002) verificam que não há formação de componentes gasosos pela degradação de patulina. Ao utilizar a toxina marcada com ${ }^{14} \mathrm{C}$, estes últimos tinham como objetivo a caracterização melhor definida das condições sob as quais $S$. cerevisiae a degrada e a identificação dos principais produtos da degradação. Todos os carbonos da molécula de patulina marcados foram rastreados nos produtos formados e concluíram que a sua degradação só ocorre quando o crescimento é anaeróbio, separando por Cromatografia Líquida de Alta Eficiência um dos principais componentes formados, o (E)-ascladiol (Figura 03). Relataram traços de (Z)-ascladiol e outros componentes não caracterizados com pesos moleculares inferiores, sendo que nenhum desses compostos era gasoso nem apresentaram volatilidade.

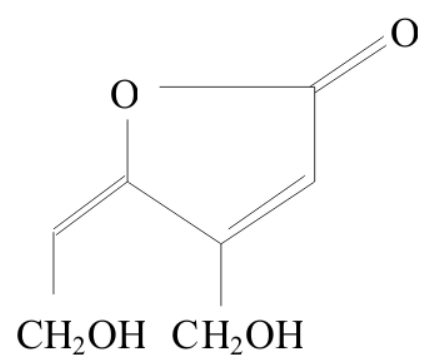

(E)-ascladiol

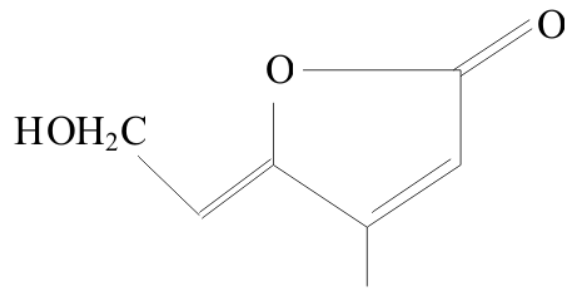

$\mathrm{CH}_{2} \mathrm{OH}$

(Z)-ascladiol

Figura 3. Produtos da degradação da patulina (MOSS; LONG, 2002).

Stinson et al. (1978) projetaram um estudo para avaliar a persistência de patulina em suco de maçã durante a fermentação utilizando para isto, oito cepas de leveduras comerciais e três diferentes processos para produção de sidra utilizados nos EUA, o Noroeste do Pacífico, que utiliza a adição de açúcar para dar início à fermentação, o da Califórnia que recebe adição de açúcar em duas etapas da fermentação e o Tradicional, sem adição de açúcar confiando na presença de açúcar do próprio suco. Somente duas cepas, pelo processo Tradicional, não foram capazes de remover patulina a um nível inferior a $50 \mu \mathrm{g} / \mathrm{L}$. Visto que este último processo não é utilizado por indústrias, suspeita-se que a contaminação apresentada em sidras comerciais se dá por alguma modificação nas etapas de produção, como a diminuição do tempo de fermentação ou a adição de suco contaminado no fermentado.

Lipowska et al. (1990) examinaram a variação na concentração de patulina durante a produção de vinho de maçã, utilizando 12 mostos com presença de patulina. Após o término da fermentação a patulina não estava presente e foi encontrado que o tempo necessário para seu desaparecimento é 
curto, chegando a 48 horas do início da fermentação alcoólica. Avaliaram também a influência da sulfitagem do suco de maçã destinado à fermentação, mostrando que $\mathrm{SO}_{2}$ conduz a uma eliminação de patulina no mosto, o que condiz com os achados de Sylos e Rodrigues-Amaya (1999).

Sumbu, Thonart e Bechet (1983) estudaram a ação da patulina sobre $S$. cerevisiae (cepa codificada como $1278 b[\alpha]$ ) verificando a existência de inibição do crescimento da levedura embora passageira, cuja duração é proporcional à concentração da toxina no meio. Demonstraram que existem dois momentos na ação da patulina em células de levedura: primeiro, a ação da toxina no metabolismo da levedura e a inibição subseqüente de crescimento e, segundo, a retomada de crescimento indicando o aparecimento de um mecanismo de resistência provavelmente associado com o desaparecimento da micotoxina durante o processo fermentativo. Também observaram que a degradação de patulina por leveduras está associada a outro fator, um mecanismo de defesa do microrganismo e dependente da síntese de proteínas, uma vez que esta micotoxina não era degradada quando adicionada simultaneamente com cicloheximida, um inibidor de síntese protéica, mas não foi concluído se essa proteína atua diretamente sobre a toxina ou se permite a síntese de uma substância responsável pela degradação. Da mesma forma, Celli (2006) verificou a degradação desta toxina em suco de maçã pelo crescimento de Saccharomyces cerevisiae (LALVIN ICV D47). Ao cultivar a levedura em meio contendo $7 \mu \mathrm{g}$ de patulina/mL, observou que nas primeiras 19,5 horas, não houve degradação. Após esse período ela passou a ser eliminada, com velocidade de 0,078 $\mu \mathrm{g} / \mathrm{mL} . \mathrm{h}$.

Ao considerar o efeito antagônico e degradador de Pichia membranifaciens e Sporobolomyces roseus na degradação de 588,4 para 290,0 $\mu \mathrm{g}$ de patulina $\left(25^{\circ} \mathrm{C} / 15\right.$ dias) em estudos preliminares (COELHO et al., 2004; LEVY et al., 2002), Coelho et al. (2007) avaliaram o efeito degradador de Pichia ohmeri 158 isolada de ecossistema natural (formigueiro) sobre toxina produzida por $P$. expansum toxigênico (107 $\mu \mathrm{g} / \mathrm{mL})$. Para tanto, foi adicionado simultaneamente $223 \mu \mathrm{g}$ de patulina e $3,0 \times 10^{6}$ células de $P$. ohmeri $158 \mathrm{em} 25 \mathrm{~mL}$ de Caldo Extrato de Malte, seguido de quantificação aos 2, 5, 10 e 15 dias de incubação a $25^{\circ} \mathrm{C}$ por Cromatografia Líquida de Alta Eficiência. A levedura diminuiu mais de $99 \%$ da toxina inicialmente adicionada após 15 dias de incubação.

Desde a descoberta de patulina, diferentes métodos vem sendo desenvolvidos com intuito de tornar a análise mais rápida e aumentar os níveis de detecção e quantificação (MOAKE; PADILLAZAKOUR; WOROBO, 2005). Atualmente, os métodos mais utilizados para quantificar patulina em produtos de fruta são baseados na separação da toxina por Cromatografia Líquida de Alta Eficiência com detector UV. Este é o método oficial adotado pela AOAC para suco de maçã (método 995.10) (AOAC, 2000) com um limite de quantificação de $5 \mu \mathrm{g} / \mathrm{L}$. Neste método o suco é extraído 3 vezes com acetato de etila, seguidos de desidratação com sulfato de sódio. $\mathrm{O}$ solvente é evaporado sob fluxo de nitrogênio gasoso à $40^{\circ} \mathrm{C}$ e o resíduo deverá ser dissolvido em acetonitrila:água (10:90) no momento da análise em Cromatografia Líquida de Alta Eficiência. A Cromatografia Líquida utiliza coluna C18 de fase reversa $(5 \mu \mathrm{m}, 250 \times 4,6 \mathrm{~mm})$ e detector UV fixado em $276 \mathrm{~nm}$. O sistema é isocratico, com fluxo de a $1 \mathrm{~mL} / \mathrm{min}$ e fase móvel acetonitrila:água (5:95). Utilizando esta técnica, Fernández-Trevejo, Verdes e Espinosa (2001a) fizeram uma curva de calibração para validação da metodologia de detecção de patulina em sucos de maçãs e obtiveram a curva $y=1952,5 x+1673,5$ com um coeficiente de correlação 0,9991. O limite de detecção foi 1,7 $\mu \mathrm{g} / \mathrm{L}$ e o de quantificação, de 5,2 $\mu \mathrm{g} / \mathrm{L}$. O valor médio da recuperação de patulina obtido por esses autores foi de $82,5 \%$, a partir de níveis de contaminação de $0,020,0,050$ e $0,100 \mu \mathrm{g} / \mathrm{mL}$.

Sheu e Shyu (1999) desenvolveram uma técnica para extração de patulina de suco de maçã, a qual utilizava diálise combinada com derivatização e acilação seguida de confirmação por Cromatografia 
Gasosa e Espectrometria de Massas. As amostras de suco de maçã adicionadas de 4-N,Ndimetilaminopiridina eram dialisadas usando cloreto de metano e anidrido acético nos tubos de diálise. A patulina era derivatizada em seu acetato e determinada utilizando Cromatografia Gasosa e Espectrometria de Massas com o íon seletivo para monitorar a concentração. A curva de calibração apresentou linearidade entre 10 e $250 \mu \mathrm{g} / \mathrm{L}$, e o limite de quantificação era $10 \mu \mathrm{g} / \mathrm{L}$. Os níveis da toxina em sucos comerciais variaram de 0 a 107,2 $\mu \mathrm{g} / \mathrm{L}$ com $77-109 \%$ de recuperação. Em 7 amostras das 10 analisadas, foi encontrada a presença de patulina. A técnica que combina extração de patulina por diálise e acilação demonstrou grande potencial podendo ser utilizada para extração de compostos em meio aquoso que necessitem derivatização antes da determinação.

Sewram et al. (2000) desenvolveram outro método para determinação de patulina, o qual empregou Cromatografia Líquida de Alta Eficiência - Espectrometria de Massas - Espectrometria de Massas com monitoramento selecionado de reação (SMR - selected reaction monitoring) utilizando a pressão atmosférica e moléculas ionizadas (APCI - atmospheric pressure chemical ionization) como íons positivos e negativos. Este método que tem como princípio a indução da dissociação por colisão (CID) apresentou um coeficiente de correlação de 0,99 quando comparado aos resultados encontrados por Cromatografia Líquida de Alta Eficiência, demonstrando sua aplicabilidade como uma nova ferramenta para análise de patulina em suco de maçã, mesmo em baixas concentrações, uma vez que quantificaram concentrações de $4 \mu \mathrm{g} / \mathrm{L}$.

Gökmen e Acar (1999) descrevem um método simultâneoparadeterminaçãodehidroximetilfurfural (HMF) e patulina em sucos de maçã. A toxina é extraída com acetato de etila, passando por coluna de clarificação (sílica mais carbonato de sódio) para remoção de interferentes e da umidade. A determinação era realizada por Cromatografia Líquida de Alta Eficiência de fase reversa usando coluna $\mathrm{C} 18$ e detector diodo. A fase móvel utilizada era acetonitrila - água (99:1, v/v) e fluxo de 1,0 mL/ min. A taxa de recuperação do HMF variou de $86 \%$ a $100 \%$, obtendo média de $94 \%$, e a da patulina variou de $94 \%$ a $125 \%$ com média de $103 \%$. Os limites de detecção eram menor que $0,01 \mathrm{mg} / \mathrm{L}$ para HMF e menor que $5 \mu \mathrm{g} / \mathrm{L}$ para patulina.

No ano seguinte, Shephard e Leggott (2000), revisam métodos analíticos disponíveis para determinação de patulina em fruta e sucos de fruta. Dentre eles estão Cromatografia Líquida de Alta Eficiência com detector UV e com detector diodo, Cromatografia Gasosa e Cromatografia em Camada Delgada. O método de escolha foi o de Cromatografia Líquida de Alta Eficiência por ser mais rápido e seguro, podendo ser aplicado a diversas amostras. Os autores apontam que futuramente métodos mais sensíveis serão necessários para confirmação de níveis mais baixos de patulina, os quais serão, provavelmente, utilizando Espectrometria de Massas e ao desenvolvimento de anticorpos patulinaespecíficos. Moake, Padilla-Zakour e Worobo (2005) complementaram as conclusões de Shephard e Leggott (2000), que há anos não existem novos métodos para quantificação da toxina, sendo que os já existentes exigem operadores treinados para manusear materiais e equipamentos, sugerindo que o desenvolvimento de um método rápido e "caseiro" seria extremamente benéfico para a indústria.

Em 2005, Boonzaaijer, Bobeldijk e Van Osenbruggen (2005) desenvolveram um método analítico seguro para determinação e quantificação de patulina utilizando técnicas convencionais, disponível à maioria dos laboratórios. O método que utiliza Cromatografia Líquida de Alta Eficiência com detector diodo, é aplicável a sucos de maçã e outros produtos mais sólidos. A separação da micotoxina se deu pela adição de hidroximetilfurfural (HMF), obtendo limite de quantificação de $25 \mu \mathrm{g} / \mathrm{L}$ ou $25 \mu \mathrm{g} /$ $\mathrm{kg}$ e um grau de recuperação de $87 \%$ para sucos de maçã. Os pesquisadores afirmam que este método tem sensibilidade para ser utilizado no controle de qualidade, uma vez que a União Européia estabelece 
um máximo de $50 \mu \mathrm{g}$ de patulina/L, porém, não pode ser utilizada para alimentos infantis, no qual é permitido um máximo de $10 \mu \mathrm{g}$ de patulina/L.

Silvaa, Schuch e Jabolnski (2007) descreveram um método rápido para separação e identificação de 5-hidroximetilfurfural (HMF) e patulina em sucos de maçã através de Cromatografia Eletrocinética Capilar Micelar, empregando sulfato de dodecil sódio (SDS) como surfactante. A separação foi feita usando o Instrumento de Eletroforese Capilar 3D (Hewlett-Packard-Stras-se 8,D-76337) equipado com detector UV. Nas condições otimizadas (tampão SDS:borato 50:50), encontraram melhor efeito na resolução do analito e no seu tempo de migração quando era aplicada a voltagem de $9 \mathrm{Kv}$. Obtiveram boa separação na linha de base entre o HMF e a patulina e limites de detecção de $30 \mu \mathrm{g} / \mathrm{L}$ e $9 \mu \mathrm{g} / \mathrm{L}$, respectivamente, mostrando ser um método útil para um amplo intervalo de concentração de HMF e de patulina em sucos de maçã, sem nenhuma desvantagem em relação ao método oficial.

\section{Considerações finais}

Apesar dos estudos não provarem conclusivamente os efeitos da patulina na saúde humana, há pouca dúvida a respeito do potencial perigo inerente a contaminação de alimentos pela toxina. Após pesquisas bastante elucidativas com relação à natureza química e biológica da patulina, fez-se avanços nos métodos de detecção e quantificação, criando maiores possibilidades de medidas de controle inteiramente eficazes. A contaminação de alimentos com patulina ainda é percebida em alimentos industrializados, assim, novas pesquisas devem continuar direcionando sua atenção para alimentos contaminados com a toxina. $\mathrm{O}$ aperfeiçoamento de técnicas de remoção e de degradação de patulina em alimentos contaminados, preservando sua qualidade e valores nutricionais, é de interesse para a segurança alimentar.

\section{Agradecimentos}

Os autores agradecem a Fundação de Amparo à Pesquisa do Estado de São Paulo (FAPESP) pelo financiamento da pesquisa.

\section{Referências}

ABRUNHOSA, L.; PATERSON, R. R. M.; KOZAKIEWICZ, Z.; LIMA, N.; VENÂNCIO, A. Mycotoxin production from fungi isolated from grapes. Letters in Applied Microbiology, Oxford, v. 32, n. 4, p. 240-242, 2001.

ANDERSEN, B.; SMEDSGAARD, J.; FRISVAD, J. C. Penicillium expansum: consistent production of patulin, chaetoglobosins, and other secondary metabolites in culture and their natural occurrence in fruit products. Journal of Agricultural and Food Chemistry, Easton, v. 52, n. 8, p. 2421-2428, 2004.

ARAFAT, W, MUSA, M. N. Patulin-induced inhibition of protein synthesis in hepatoma tissue culture. Research Communications in Molecular Pathology \& Pharmacology, Westbury, v. 87, n. 2, p. 177-186, 1995.

ARGENTA, L. C. Concentração de etileno interno e maturação de maçãs cvs. Gala, Golden delicious e Fuji. Revista Brasileira de Fruticultura, Jaboticabal, v. 15 n. 1, p. 125-132, 1993.

ASSOCIAÇÃO BRASILEIRADOS PRODUTORES DE MAÇÃ - ABPM. Caderno estatístico. 2004. Disponível em: <http://www.abpm.org.br>. Acesso em: 18 ago. 2008.

ASSOCIATION OF OFFICIAL ANALYTICAL CHEMISTS - AOAC. AOAC Official Method 995.10: determinación de patulina en frutas y alimentos. Official methods of analysis of AOAC International. 17. ed. Washington: AOAC International, 2000.

AYTAC, S. A.; ACAR, J. Einflub von L-Ascorbinsäure und Schwefeldioxidzusatz auf die Stabilität von Patulin in Apfeläften und Pufferlösungen. Ernährung, Berlin, v. 1, p. 15-17, 1994.

BAERT, K.; CHITUNDU, K.; DE MEULENAER, B.; DEVLIEDHERE, F. Incidence of patulin in organic and conventional apple juice marketed in Belgium. In: INTERNATIONAL IUPAC SYMPOSIUM ON MYCOTOXINS AND PHYCOTOXINS, 11., 2004, Bethesda. Proceedings... Bethesda: IUPAC, 2004. p. 37.

BATTA, Y. A. Postharvest biological control of apple gray mold by Trichoderma harzianum Rifai formulated 
in an invert emulsion. Crop protection, Guildford, v. 23, n. 1, p. 19-26, Jan. 2004.

BERETTA, B.; GAIASCHI, A.; GALLI, C. L.; RESTANI, P. Patulin in apple-based foods: occurrence and safety evaluation. Food Additives \& Contaminants, London, v. 17, n. 5, p. 399-406, 2000.

BISSESSUR, J.; PERMAUL, K.; ODHAV, B. Reduction of patulin during apple juice clarification. Journal of Food Protection, Des Moines, v. 64, n. 8, p. 1216-1219, 2001.

BOLGER, M. Integration of risk assessment and management. In: SEMINAR ON THE SAFETY/RISK ANALYSIS OF CONTAMINANTS; GENOTOXIC CARCINOGENS, 2002. Rotterdam: FAO/WHO, p.15, 2002.

BOONZAAIJER, G.; BODELDIJK, I.; VAN OSENBRUGGEN, W. A. Analysis of patulin in dutch food, an evaluation of a SPE based method. Food Control, Guildford, v. 16, n. 7, p. 587-591, 2005.

BRACKETT, R. E.; MARTH, E. H. Patulin in apple juice from roadside stands in Wisconsin. Journal of Food Protection, Des Moines, v. 42, n. 11, p. 862-863, 1979.

BRACKMANN, A.; MAZARO, S. M.; LUNARDI, R. Armazenamento da maçã cv. Golden Delicious em atmosfera controlada com altas concentrações de $\mathrm{CO}_{2} \mathrm{e}$ ultra-baixas de $\mathrm{O}_{2}$. Ciência Rural, Santa Maria, v. 26, n. 2, p. 215-219, 1998.

BRASIL. Instrução Normativa $n^{\circ} 1$, de 7 de janeiro de 2000. Estabelece o regulamento técnico para a fixação dos padrões de identidade e qualidade para a polpa de fruta. Diário Oficial [da] República Federativa do Brasil, Brasília, 10 jan. 2000, Seção 1, n. 6, p. 54-58.

BRASIL. Ministério da Agricultura, Pecuária e Abastecimento - MAPA. Programa nacional de erradicação da Cydia pomonella. 2007. Disponível em: $<$ www.agricultura.gov.br>. Acesso em: 15 maio 2008.

. Suco de maçã. 2000. Disponível em: <www. agricultura.gov.br>. Acesso em: 20 ago. 2005.

BURDA, K. A. Research Note: Incidence of patulin in apple, pear, and mixed fruit-products marketed in New South Wales. Journal of Food Protection, Des Moines, v. 55, n. 10, p. 796-798, 1992.

BURROUGHS, L. F. Stability of patulin to sulfur dioxide and to yeast fermentation. Journal of AOAC International, Arlington, v. 60, n. 1, p. 100-103, 1977.

CELLI, M. G. Patulina em maçãs e em produtos derivados. Aspectos sanitários e controle empregando Saccharomyces Cerevisiae. 2006. Dissertação. (Mestrado em Ciência e Tecnologia de Alimentos) - Departamento de Engenharia de Alimentos da Universidade Estadual de Ponta Grossa, Ponta Grossa.

CHEN, L.; INGHAM, B. H.; INGHAM, S. C. Survival of Penicillium expansum and Patulin Production on Stored Apples after Wash Treatments. Journal of Food Science, Chicago, v. 69, n. 8, p. 669-675, 2004.

CHERAGHALI, A. M.; MOHAMMADI, H. R.; AMIRAHMADI, M.; YAZDANPANAH, H.; ABOUHOSSAIN, G.; ZAMANIAN, F.; KHANSARI, M. G.; AFSHAR, M. Incidence of patulin contamination in apple juice produced in Iran. Food Control, Guildford, v. 16, n. 7, p. 165-167, 2005.

COELHO, A. R. Controle de Penicillium expansum/ biodegradação de patulina: perfil cromatográfico de composto bioativo de leveduras killer visando aplicação pós-colheita. 2005. Tese. (Doutorado em Ciência de Alimentos) - Departamento de Ciências de Alimentos e Medicamentos da Universidade Estadual de Londrina, Londrina, 2005.

COELHO, A. R., CELli, M. G., ONO, E. Y. S., WOSIACKI, G., HOFFMANN, F. L., PAGNOCCA, F. C., HIROOKA, E. Y. Penicillium expansum versus antagonist yeasts and patulin degradation. Brazilian Archives of Biology and Technology, Curitiba, v. 50, n. 4, p. 725-733, 2007.

COELHO, A. R.; LEVY, R. M.; HOFFMANN, F. L.; TANIWAKI, M. H.; KMELMMEIER, C.; PAGNOCCA, F. C.; HIROOKA, E. Y. Patulin producing Penicillium expansum vs. antagonistic yeasts with perspectives of biocontrol in the post-harvest of fruits. In: INTERNATIONAL IUPAC SYMPOSIUM ON MYCOTOXINS AND PHYCOTOXINS, 11., 2004, Bethesda. Proceedings... Maryland: IUPAC, 2004. p. 99.

COMMISSIONOFTHEEUROPEANCOMMUNITIES. Comission Regulation (EC) No. 1425/2003, of 11 August 2003. Amending Regulation (EC) $\mathrm{N}^{\circ} 466 / 2001$ as regards patulin. (Text with EEA relevance). Disponível em: $<\mathrm{http}$ ://www.fsai.ie/legislation/food/eu_docs/contam foodstuffs/General\%20Provisions/Reg14 $25.2003 . p d f>$. Acesso em: 21 jun. 2008.

CONWAY, W. S.; LEVERENTZ, B.; JANISIEWICZ, W. J.; BLODGETT, A. B.; SAFTNER, R. A.; CAMP, M. J. Integrating heat treatment, biocontrol and sodium bicarbonate to reduce post-harvest decay of apple caused by Colletotrichum acutatum and Penicillium expansum. Postharvest Biology and Technology, New York, v.34, n. 1, p.11-20, 2004. 
DEMIRCI, M.; ARICI, M.; GUMUS, T. Presence of patulin in fruit and fruit juices produced in Turkey. Ernaehrungsumschau, Berlin, v. 50, n. 7, p. 262-263, 2003.

DOMBRINK-KURTZMAN, M. A.; BLACKBURN, J. A. Evaluation of several culture media for production of patulin by Penicillium species. International Journal of Food Microbiology, Amsterdam, v. 98, n. 3, p. 241-248, 2005.

DRILLEAU, J. F.; BOHOUN, G. La patuline dans les produits cidricoles. Comptes rendus des seances de l' Academie d'Agriculture de France, Paris, v. 59, p. 10311037, 1973.

ENGEL, G.; TEUBER, M. Patulin and other small lactones. In: BETINA, V. Mycotoxins: production, isolation, separation and purification. Amsterdam: Elsevier Science, 1984. p. 290-299.

FOOD AGRICULTURE ORGANIZATION - FAO. Committee on agriculture. Disponível em: <http://www. fao.org>. Acesso em: 02 jun. 2008.

FERNÁNDEZ-TREVEJO, E. O.; ARIAS VERDÉS, J. A.; SERSA ESPINOSA, R. Validación de un método para la determinación de patulina em jugos y purês de frutas por HPLC. Revista Cubana de Alimentación y Nutrición, Habana, v. 15, n. 1, p. 20-25, 2001 a.

Presence of patulin in fruit purees and juices. Alimentaria, Madrid, v. 38, n. 321, p. 133-135, 2001 b.

FLORIANOWICZ, T. Antifungal activity of some microorganisms against Penicillium expansum. Europe Food Research Technology, Berlin, v. 212, n. 3, p. 282286, 2001.

FONSECA, H. Micotoxinas on line. Disponível em: $<$ www.micotoxinas.com.br>. Acesso em: 28 jun. 2008.

FOOD STANDARDS AGENCY - FSA. Patulin not detected in cider, 2003. Disponível em: $<$ http://www. food.gov.uk> Acesso em: 7 out. 2005.

FUNDAÇÃO CARGILL. Relatório Anual. Campinas: Fundação Cargill, 1983.

GALCIA-CLOSAS, R.; BERENGER, A.; JOSE, T. M.; JOSE, S. M.; QUIRO, J. R.; NAVARRO, C.; AMAUD, R.; DORRONSORO, M.; DOLORES, C. M.; BARRICARTE, A.; ARDANAZ, E.; AMIANO, P.; MARTINEZ, C.; AGUDO, A.; GINZALES, C. Dietary souces of vitamin C, Vitamin E, and specific carotenoids in Spain. British Journal of Nutrition, Cambridge, v. 91, n. 6, p.1005-1011, 2004.

GÖKMEN, V.; ACAR, J. An Investigation on the Relationship between Patulin and Fumaric Acid in Apple
Juice Concentrates. Lebensmittel Wissenschaft und Technologie, London, v. 31, n. 5, p. 480-483, 1998 a.

Incidence of patulin in apple juice concentrates products in Turkey. Journal of Chromatography A, Amsterdam, v. 815, n. 1, p. 99-192, 1998 b.

Long-term survey of patulin in apple juice concentrates produced in Turkey. Food Additives \& Contaminants, London, v. 17, n. 11, p. 933-936, 2000.

Simultaneous determination of 5hydroxymethylfurfural and patulin in apple juice by reversed-phase liquid chromatography. Journal of Chromatography A, Amsterdam, v. 847, n. 1-2, p. 69-74, 1999.

GÖKMEN, V.; ARTIK, N.; ACAR, J.; KAHRAMAN, N.; POYRAZOGLU, E. Effects of various clarification treatments on patulin, phenolic compound and organic acid compositions of apple juice. European Food Research \& Technology, Berlin, v. 213, n. 3, p. 194-199, 2001.

GÖNÇALEZ, E.; PINTO, M. M.; FELICIO J. D. Análise de micotoxinas no instituto biológico de 1989 a 1999. Biológico, São Paulo, v. 63, n. 1-2, p. 15-19, jan./dez., 2001.

GRIFFIN; D. H. Fungal physiology. 2. ed. Nova York: Wiley-Liss, 1993.

GROOTWASSINK, J. W. D.; GAUCHER, G. M. De novo biosynthesis of secondary metabolism enzymes in homogeneous cultures of Penicillium urticae. Journal of Bacteriology, Washington, v. 141, n. 2, p. 443-455, 1980.

HARWIG, J.; CHEN, Y. K.; KENNEDY, B. P. C.; SCOTT, P. M. Occurrence of patulin and patulinproducing strains of Penicillium expansum in natural rots of apple in Canada. Canadian Institute of Food Science and Technology, Ottawa, v. 6, n. 1, p. 22-25, 1973.

HASAN; H. A. H. Patulin and aflatoxin in brown rot lesion of apple fruits and their regulation. World Journal of Microbiology \& Biotechnology, Oxford, v. 16, n. 7, p.607-612, 2000.

HATEZ, F.; GAYE, F. Inhibition of translation in reticulocyte by the mycotoxin patulin. FEBS Letters, Amsterdam, v. 95, n. 2, p. 252-256, 1978.

HEFNAWY, M. A.; ABOU-ZEID, A. M. Differential adaptation of membranes of two osmotolerant fungi, Aspergillus chevalieri and Penicillium expansum to high sucrose concentrations. Acta Microbiologica Polonica, Warszawa, v. 52, n. 1, p. 53-64, 2003.

HOPKINS, J. The toxicological hazards of patulin. Food and Chemical Toxicology, Oxford, v. 31, n. 6, p. 455-459, 1993. 
HUEBNER, H. J.; MAYURA, K.; PALLARONI, L.; AKE, C. L.; LEMKE, S. L.; HERRERA, P.; PHILLIPS, T. D. Development and characterization of a carbonbased composite material for reducing patulin levels in apple juice. Journal of Food Protection, Des Moines, v. 63, n. 1, p. 106-110, 2000.

INSTITUTO BRASILEIRO DE GEOGRAFIA E ESTATÍSTICA - IBGE. Levantamento sistemático da produção agrícola - LSPA. 2007. Disponível em: $<\underline{\text { http:// }}$ www.ibge.gov.br>. Acesso em: 10 jul. 2008.

INSTITUTO BRASILEIRO DE FRUTAS - IBRAF. Novos horizontes para a fruticultura brasileira. 2005. Disponível em: $<$ http://www.ibraf.org.br $>$. Acesso em: 10 jul. 2008.

Volume das exportações de frutas cresce 14\%. 2008. Disponível em: $<$ http://www.ibraf.org.br $>$. Acesso em: 10 jul. 2008.

IHA, M. H.; SABINO, M. Determination of patulin in apple juice by liquid chromatography. Journal of $A O A C$ International, Arlington, v. 89, n. 1, p. 139-143, 2008.

ITO, R.; YAMAZAKI, H.; INOUE, K.; YOSHIMURA, Y.; KAWAGUCHI, M.; NAKAZAW, H. Development of liquid chromatography-electrospray mass spectrometry for the determination of patulin in apple juice: Investigation of this contamination in Japan. Journal of Agricultural and Food Chemistry, Easton, v. 52, n. 25, p. 7464-7468, 2004.

IWAHASHI, Y.; HOSODA, H.; PARK, J. H.; LEE, J. H.; SUZUKI, Y.; KITAGAWA, E.; MURATA, S. M.; JWA, N. S.; GU, M. B.; IWAHASHI, H. Mechanisms of Patulin Toxicity under Conditions That Inhibit Yeast Growth. Journal of Agricultural and Food Chemistry, Easton, v. 54, n. 5, p. 1936-1942, 2006.

JACKSON, L. S.; BEACHAM-BOWDEN, T.; KELLER, S. E.; ADHIKARI, C.; TAYLOR, K. T.; CHIRTEL, S. J.; MERKER, R. I. Apple quality, storage, and washing treatments affect patulin levels in apple cider. Journal of Food Protection, Des Moines, v. 66, n. 4, p. 618-624, 2003.

JANISIEWICZ, W. J.; LEVERENTZ, B.; CONWAY, W. S.; SAFTNER, R. A.; REED, A. N.; CAMP, M. J. Control of bitter rot and blue mold of apples by integrating heat and antagonist treatments on MCP treated fruit stored under controlled atmosphere conditions. Postharvest Biology and Technology, New York, v. 29, n. 2, p. 129143, 2003.

JIMINEZ, M.; MATEO, R.; QUEROL, A.; HUERTA, T.; HERNANDEZ, E. Mycotoxins and mycotoxigenic moulds in nuts and sunflower seeds for human consumption. Mycopathologia, Den Haag, v. 115, n. 2, p. 121-127, 1991.
KADAKAL, C.; NAS, S. Effect of activated charcoal on patulin, fumaric acid and some other properties of apple juice. Nahrung-Food, Malden, v. 46, n. 1,p. 31-33, 2002.

KADAKAL, C.; NAS, S.; EKINCI, R. Ergosterol as a new quality parameter together with patulin in raw apple juice produced from decayed apples. Food Chemistry, London, v. 90, n. 1-2, p. 1-6, 2004

KARLOVSKY, P. Biological detoxification of fungal toxins and its use in plant breeding, feed and food production. Natural Toxins, New York, v. 7, n. 1, p. 1-23, 1999.

KOCA, N.; EKSI, A. Reduction of patulin in apple juice concentrates during storage. Journal of Food Safety, Malden, v. 25, n. 1, p. 1-8, 2005.

KOZLOWSKA, K.; JERUSZKA, M.; MATUSZEWSKA, I.; ROSZKOWSKI, W.; BARYLKO-PIKIELNA, N.; BRZOZOWSKA, A. Hedonic tests in different locations as predictors of apple juice consumption at home in elderly and young subjects. Food Quality and Preference, Oxford, v. 14, n. 8, p. 653-661, 2003.

KRYGER, R. A. Volatility of patulin in apple juice. Journal of Agricultural and Food Chemistry, Easton, v. 49, n. 8, p. 4141-4143, 2001.

LAI, C. L.; FUH, Y. M.; SHIH, Y. C. Detection of mycotoxin patulin in apple juice. Journal of Food and Drug Analysis, Taiwan, v. 8, n. 2, p. 85-96, Aug. 2000.

LAIDOU, A.; THANASSOULOPOULOS, C. C.; LIAKOPOULOU-KYRIAKIDES, M. Diffusion of patulin in the flesh of pears inoculated with four postharvest pathogens. Journal of Phytopathology, Berlin, v. 149, n. 7-8, p. 457-461, 2001.

LEGGOTT, N. L.; SHEPHARD, G. S. Patulin in South African commercial apple products. Food Control, Guildford, v. 12, n. 2, p. 73-76, 2001.

LEGGOTT, N. L.; SHEPHARD, G. S.; STOCKENSTROM, S.; STAAL, E.; VAN SCHALKWYK, D.J. The reduction of patulin in apple juice by three different types of activated carbon. Food Additives \& Contaminants, London, v. 18, n. 9, p. 825829, 2001.

LEITÃO, M. F. F. Conservadores em alimentos e fatores que afetam sua eficiência no controle de microrganismos. Coletânea do Instituto de Tecnologia de Alimentos, Campinas, v. 20, n. 2, p. 116-127, jul./dez. 1990.

LEVY, R. M.; HAYASHI, L.; CARREIRO, S.C.; PAGNOCCA, F. C.; HIROOKA, E. Y. Inhibition of mycotoxigenic Penicillium sp. and patulin biodegradation by yeast strains. Revista Brasileira de Armazenamento, Viçosa, v. 27, n. 1, p. 41-47, 2002. 
LEVY, R. M.; SILVA, R. S. F.; PAGNOCCA, F. C.; HIROOKA, E. Y. Ensaio fatorial da atividade inibitória de Penicillium por leveduras em frutos de maçã. Brazilian Journal of Food Technology, Campinas, v. 3, n. 47, p. 145-150, 2000.

LINDROTH, S.; NISKANEN, A. Comparison of potential patulin hazard in home-made and commercial apple products. Journal of Food Science, Chicago, v. 43, n. 2, p. 446-448, 1978.

LIPOWSKA, T.; GOSZCZ, H.; KUBACKI, S.; JANUSZEWSKI, T. Studies of changes in patulin content during apple wine production and must sulphurization. Journal of Food Processing and Preservation, Westport, v. 14, n. 1, p. 7-19, 1990.

MACDONALD, S.; LONG, M.; GILBERT, J.; FELGUEIRAS, I. Liquid Chromatographic Method for Determination of patulin in clear and cloudy apple juices and apple puree - Collaborative Study. Journal of AOAC International, Arlington, v. 83, n. 6, p. 1387-1394, 2000.

MAHFOUD, R.; MARESCA, M.; GARMY, N.; FANTINI, J. The mycotoxin patulin alters the barrier function of the intestinal epithelium: mechanism of action of the toxin and protective effects of glutathione. Toxicology and Applied Pharmacology, San Diego, v. 181, n. 3, p. 1209-1218, 2002.

MAJERUS, P.; KAPP, K. (Coord.). Reports on tasks for scientific cooperation, task 3.2.8 - Assessment of dietary intake of patulin by the population of EU member States. 2002. Disponível em: <http://www.europa.eu.int/comm/ food/fs/scoop/3.2.8 en.pdf $>$. Acesso em: 15 fev. 2007.

MALMAURET, L.; PARENT-MASSIN, D.; HARDY, J.-L.; VERGER, P. Contaminants in organic and conventional foodstuffs in France. Food Additives \& Contaminants, London, v. 19, n. 6, p. 524-532, 2002.

MARÍN, S.; MORALES, H.; HASAN, H. A. H.; RAMOS, A. J.; SANCHIS, V. Patulin distribution in Fuji and Golden apples contaminated with Penicillium expansum. Food Additives \& Contaminants, London, v. 23, n. 12, p. 1316-1322, 2006.

MARTINS, M. L.; GIMENO, A., MARTINS, H. M.; BERNARDO, F. Co-occurrence of patulin and citrinin in Portuguese apples with rotten spots. Food Additives \& Contaminants, London, v. 19, n. 6, p. 568-574, 2002.

MCKINLEY, E. R.; CARLTON, W. W.; BOON, G. D. Patulin mycotoxicosis in the rat: toxicology, pathology, and clinical pathology. Food and Chemical Toxicology, Oxford, v. 20, n. 3, p. 289-300. 1982.

MELLO, L. M. R. Produção e mercado brasileiro de maçã, 2004. Disponível em: <www.cnpuv.embrapa.br>. Acesso em: 25 ago. 2007. Comunicado Técnico, 50.
MIURA, S.; HASUMI, K.; ENDO, A. Inhibition of protein prenylation by patulin. Federation of European Biochemical Societies, Oxford, v. 318, n. 1, p. 88-90, 1993.

MOAKE, M. M.; PADILLA-ZAKOUR, O.; WOROBO, R. W. Comprehensive review of patulin control methods in foods. Comprehensive Reviews in Food Science and Food Safety, Chicago, v. 4, n. 1, p. 8-21, 2005.

MORALES, H.; MARÍN, S.; ROVIRA, A.; RAMOS, A. J.; SANCHIS, V. Patulin accumulation in apples by Penicillium expansum during postharvest stages. Letters in applied microbiology, Oxford, v. 44, n. 1, p. 30-35, 2007.

MOSS, M. O. Fungi, quality and safety issues in fresh fruits and vegetables. Applied Microbiology, Oxford, v. 104, n. 5, p. 1239-1243, 2008.

. Mycotoxins. Mycological Research, Cambridge, v. 100, n. 5, p.513-523, 1996.

MOSS, M. O.; LONG, M. T. Fate of patulin in the presence of the yeast Saccharomyces cerevisiae. Food Additives \& Contaminants, London, v. 19, n. 4, p. 387399, 2002.

MOULE, Y.; HATEY, F. Mechanism of the in vitro inhibition of transcription by patulin, a mycotoxin from Byssochlamys nivea. FEBS Letters, Amsterdam, v. 74, n. 1, p. 121-125, Feb. 1977.

MUTLU, M.; HIZARCIOGLU, N.; GÖKMEN, V. Patulin Adsorption Kinetics on Activated Carbon, Activation Energy and Heat of Adsorption. Journal of Food Science, Chicago, v. 62, n. 1, p. 128-130, 1997.

NORTHOLT, M. D.; VAN EGMOND, H. P.; PAULSCH, W. E. Patulin production by some fungal species in relation to water activity and temperature. Journal of Food Protection, Ames, v. 41, n. 11, p. 885-890, 1978.

NUNES, C.; USALL, J.; TEIXIDÓ, N.; VIÑAS, I. Biological control of post-harvest pear diseases using a bacterium, Pantoea agglomerans CPA-2. InternationalJournal of Food Microbiology, Amsterdam, v. 70, n. 1-2, p. 53-61, 2001.

OKULL, D. O.; LABORDE, L. F. Activity of electrolyzed oxidizing water against penicilium expansum in suspension and on wounded apples. Journal of Food Science, Chicago v. 69, n. 1, p. 23-27, 2004.

OUGH, C. S.; CORISON, C. A. Measurement of patulin in grapes and wines. Journal of Food Science, Chicago, v. 45 , n. 3 , p. $476-478,1980$.

PIEMONTESE, L.; SOLFRIZZO, M.; VISCONTI, A. Occurence of patulin in conventional e organic fruit producing in Italy and subsequent exposure assessment. 
Food Additives \& Contaminats, London, v. 22, n. 5, p. 437-442, 2005.

PRADO, E. C. Empresas produtoras de sucos de frutas investem em produção de matéria- prima para crescer. Exportar \& Gerência, Brasília, n. 15, p. 18-21, mar. 2000.

PRADO, G.; OLIVEIRA, M. S.; CUNHA, M. R.; GOMIDES, M. F.; ABRANTES, F. M.; SANTOS, L. G.; SOARES, T. V.; BARROSO, R. E. S. Ocorrência de patulina em suco de maçã por cromatografia líquida de alta eficiência. Revista do Instituto Adolfo Lutz, São Paulo, v. 59, n. 1-2, p. 21-25, 2000.

PRIETA, J.; MORENO, A.; DÍAZ, S.; SUAREZ, G.; DOMINGUEZ, L. Survey of patulin in apple juice and children's apple food by the diphasic dialysis membrane procedure. Journal of Agricultural and Food Chemistry, Washington, v. 42, n. 8, p. 1701-1703, 1994.

RICHARD, J.; PAYSE, G.; DESJARDINS, A. E.; MARAGAS, C.; NORRED, W.; PESTKA, J. J.; PHILLIPS, T. D.; VAN EGMOND, H. P.; VARDON, P. J; WHITAKER, T. B.; WOOD, G. Mycotoxins, risk in plant, animal and human systems. Council for Agricultural Science and Technology, Ames, n. 139, p. 101-103, 2003.

RILEY, R. T., SHOWKER, J. L. The mechanism of patulin's cytotoxicity and the antioxidant activity of indole tetramic acids. Toxicology and Applied Pharmacology, San Diego, v. 109, n. 1, p. 108-26, 1991.

RITIENI, A. Patulin in Italian commercial apple products. Journal of Agricultural and Food Chemistry, Washington, v. 51, n. 20, p. 6086-6090, 2003.

ROSS, G. Patulina: parâmetros que influem na produção, detoxicação e considerações sobre microbiota fúngica em maçã (Malus domestica Borkhausen). 1995. Tese (Mestrado em Ciência de Alimentos) - Universidade Estadual de Londrina, Londrina.

ROSS, G. U.; TANIWAKI, M. H.; SABINO, M.; VIZONI, T.; HIROOKA, E. Y. Produção de patulina em maçã (Malus domestica Borkhausen), cultivares gala e Fuji, inoculadas com Penicillium spp. Ciência e Tecnologia de Alimentos, Campinas, v. 18, n. 1, p. 82-87, jan./abr., 1998.

RYCHLIK, M.; SCHIEBERLE, P. Model studies on the diffusion behavior of the mycotoxin patulin in apples, tomatoes, and wheat bread. European Food Research \& Technology, Berlin, v. 212, n. 3, p. 274-278, 2001.

SANHUEZA, R. M.; KRETZCHMAR, A. A.; BORSÓI, M. Avaliação de organismos antagônicos a Penicillium expansum em maçãs cv. Fuji em pós colheita. Fitopatologia Brasileira, Brasília, v. 17, n. 4, p. 423-429, 1992.
SCUSSEL, V. M. Patulina. In: . Micotoxinas em alimentos. Florianópolis: Insular, 1998. p. 47-48.

SELMANOGLU, G.; KOCKAYA, E. A. Investigation of the effects of patulin on thyroid and testis, and hormone levels in growing male rats. Food and Chemical Toxicology, Oxford, v. 42, n. 5, p. 721-727, 2004.

SEWRAM, V.; NAIR, J. J.; NIEUWOUDT, T. W.; LEGGOTT, N. L.; SHEPHARD, G. S. Determination of patulin in apple juice by high-performance liquid chromatography-atmospheric pressure chemical ionization mass spectrometry. Journal of Chromatography $A$, Amsterdam, v. 897, n. 1-2, p. 365-374, 2000.

SHARMA, R. P. Immunotoxicity of mycotoxins. Journal of Dairy Science, Champaign, v. 76, n. 3, p. 892-897, 1993.

SHEPHARD, G. S.; LEGGOT, N. L. Chromatographic determination of the mycotoxin patulin in fruit and fruit juices. Journal of Chromatography A, Amsterdam, v. 892, n. 1-2, p. 17-22, 2000.

SHEU, F.; SHYU, Y. T. Analysis of Patulin in Apple Juice by Diphasic Dialysis Extraction with in Situ Acylation and Mass Spectrometric Determination. Journal of agricultural and food chemistry, Easton, v. 47, n. 7, p. 2711-2714, 1999.

SHILIHA, H.; ASKAR, A. Patulin in apple juice and children's apple food. Fruit Processing, Schönborn, n. 5, p. 164-167, 1999.

SHOLBERG, P. L.; BEDFORD, K.; STOKES, S. Sensitivity of Penicillium spp. and Botrytis cinerea to pyrimethanil and its control of blue and gray mold of stored apples. Crop protection, Guildford, v. 24, n. 2, p. 127-134, fev. 2005.

SILVAA, S.J.N.; SCHUCH, P. Z.; JABLONSKI, A. Determinação simultânea de 5-hidroximetilfurfural e patulina, em suco de maçã, por eletrocromatografia micelar. Higiene Alimentar, São Paulo, v. 21, n. 155, p. 92-96, out. 2007.

SIMÃO, S. Tratado de fruticultura. Piracicaba: Fundação de Estudos Agrários Luiz de Queiroz, 1998.

STEINER, I.; WERNER, D.; WASHUTTI, J. Patulin in fruit juices. Part 1. Analysis and control in Austrian apple and pear juices. Ernaehrung, Berlin, v. 23, p. 202-208, 1999.

STINSON, E. E.; OSMAN, S. F.; BILLS, D. D. Water-soluble products from patulin during alcoholic fermentation of apple juice. Journal of Food Science, Chicago, v. 44, n. 33, p. 789-796. May/Jun., 1979.

STINSON, E. E.; OSMAN, S. F.; HUHTANEN, C. N.; BILLS, D. D. Disappearance of patulin during alcoholic 
fermentation of apple juice. Applied and Environmental Microbiology, Washington, v. 36, n. 4, p. 620-622. Oct., 1978.

STOTT, W. T.; BULLERMAN, L. B. Influence of carbohydrate and nitrogen source on patulin production by Penicillium patulum. Applied Microbiology, Washington, v. 30 , n. 5 , p. $850-854,1975$.

SUMBU, Z. L.; THONART, P.; BECHET, J. Action of patulin on a yeast. Applied and Environmental Microbiology, Washington, v. 45, n. 1, p. 110-115, jan. 1983.

SYDENHAM, E. W.; VISMER, F. H.; WALTER, F. O.; MARASAS, N. B.; SCHELECHTER, M. Reduction of patulin in apple juice samples: influence of initial processing. Food Control, Guildford, v. 6, n. 4, p. 195200, 1995.

SYLOS, C. M.; RODRIGUES-AMAYA, D. B. Incidence of patulin in fruits and fruit juices marketed in Campinas, Brazil. Food Additives \& Contaminants, London, v. 16, n. 2, p. 71-74, 1999.

TANGNI, E. K.; THEYS, R.; MINGNOLET, E.; MAUDOUX, M.; MICHELET, J. Y.; LANRONDELLE, Y. Patulin in domestic and imported apple-based drinks in Belgium: occurrence and exposure assessment. Food Additives \& Contaminats, London, v. 20, n. 5, p. 482489, 2003.

TAVARES, S. C. C. H. Controle biológico clássico de patógenos de frutas no Brasil - situação atual. In: SIMPÓSIO DE CONTROLE BIOLÓGICO, 5., 1996, Foz do Iguaçú. Anais... Foz do Iguaçú: SINCOBIOL, 1996. p. 57-68.

TEIXIDO, N.; USALL, J.; VINAS, I. Efficacy of preharvest and postharvest Candida sake biocontrol treatments to prevent blue mould on apples during cold storage. International Journal of Food Microbiology, Amsterdam, v. 50, n. 3, p. 203-210, 1999.

TODA FRUTA. Característica da Maçã. Disponível em: <http://www.todafruta.com.br $>$. Acesso em: 20 jun. 2008.

TRUCKSESS, M. W.; TANG, Y. Solid-phase extration method for patulin in apple juice and unfiltered apple juice. Journal of AOAC International, Arlington, v. 82, n. 5, p. 1109-1113, 1999.

TU, K.; NICOLAI, B.; BAERDEMAEKER, J. Effects of relative humidity on apple quality under simulated shelf temperature storage. Science Horticultural, Amsterdam, v. 85, n. 3 , p. $217-229,2000$

UNITED KINGDOM. Ministry of Agriculture Fisheries and Food. News releases: MAFF and industry work together on food safety. London, 1998.
Patulin in apple juice: 1993 Survey. Food Surveillance Information Sheet, Lodon, n. 16, Oct. 1993. Disponível em: <http://archive.food.gov.uk/maff/ archive/food/infsheet/1993/no16/16pat.htm>. Acesso em: 26 Nov. 2008.

Survey of apple juice for patulin. Food Surveillance Information Sheet, London, n. 173, Apr. 1999. Disponível em: <http://archive.food.gov.uk/maff/ archive/food/infsheet/1999/no173/173pat.htm>. Acesso em: 26 Nov. 2008.

USALL, J.; TEIXIDO, N.; TORRES, R.; DE ERIBE, X. O.; VINAS, I. Pilot tests of Candida sake (CPA-1) applications to control postharvest blue mold on apple fruit. Postharvest Biology and Technology, Amsterdam, v. 21, n. 2, p. 147-156, 2001.

WALKER, G.; MCLEOD, A.; HODGSON, V. Interactions between killer yeast and pathogenic fungi. FEMS Microbiology Letters, Amsterdam, v. 127, n. 3, p.213-222, 1995.

WATKINS, C.; HARKER, R.; BROOKFIELD, P.; TUSTIN, S. Maturity of Royal Gala, Breabum and FujiThe New Zealand Experience. Annual Washington Tree Fruit Postharvest Conference, Wenatchee, v. 9, n. 1, p. 16-19, 1993.

WATKINS, K. L.; FAZERAS, G.; PALMER, M. V. Patulin in Australian apple juice. Food Australia, North Sydney, v. 42, n. 9, p. 438-439, 1990.

WICHMANN, G.; HERBARTH, O.; LEHMANN, I. The mycotoxins citrinin, gliotoxin, and patulin affect interferon-_ rather than interleukin-4 production in human blood cells. Environmental Toxicology, New York, v. 17, n. 3, p. 211-218, 2002.

WILSON, D. M.; NUOVO, G. J. Patulin production in apples decayed by Penicillium expansum. Applied Microbiology, Oxford, v. 26, n. 1, p. 124-125, 1973.

WISNIEWSKI, M. E.; WILSON, C. L. Biological control of post-harvest diseases of fruits and vegetables: recent advances. HortScience, Alexandria, v. 27, n. 1, p.94-98, 1992.

WOSIACKI, G.; DEMIATE, I. M.; CHERUBIM, R. A. Brazilian apple juice industry. Fruit Processing, Schönborn, v. 5, n. 5, p. 10-14, 1995.

WOSIACKI, G.; NOGUEIRA, A.; SILVA, N. C. C. Brazilian apple production - a few years later. Fruit Processing, Schönborn, v. 10, n. 12, p. 472-475, dez. 2000.

WOSIACKI, G.; NOGUEIRA, A.; SILVA, N. C. C.; DENARDI, F.; CAMILO, A. P. Apple varieties growing inn subtropical áreas. The situation in Santa Catarina - 
Brazil. Fruit Processing, Schönborn, v. 12, n. 1, p. 19-28, Jan., 2002.

YURDUN, T., OMURTAG, G. Z.; ERSOY, Ö. Incidence of patulin in apple juices market in Turkey. Journal of Food Protection, Des Moines, v. 64, n. 11, p. 1851-1853, 2001.
ZEGOTA, H.; ZEGOTA, A.; BACHMAN, S. Effect of irradiation on the patulin content and chemical composition of apple juice concentrate. Lebensm Unters Forsch, Heidelberg, v. 187, n. 3, p. 235-238, Sep. 1988. 
